\title{
LA REPRODUCCIÓN DE LOS OFICIOS. DE LA ORGANIZACIÓN GREMIAL A LA ESCUELA NACIONAL DE ARTES Y OFICIOS DE HOMBRES EN LA CIUDAD DE MÉXICO, 1780-1915
}

\author{
Sonia Pérez Toledo \\ Universidad Autónoma Metropolitana-Iztapalapa
}

LA REPRODUCCIÓN DE LOS OFICIOS

$\mathrm{D}$

urante el largo periodo virreinal, la enseñanza de los oficios artesanales de los talleres ubicados en los núcleos urbanos y en los obrajes establecidos en las zonas rurales estuvo principalmente a cargo de los maestros de los oficios. Con excepción del trabajo doméstico y de cierta manera también del trabajo a domicilio, ${ }^{1}$ la figura central para la reproducción de la mano de obra fue el maestro artesano del pequeño taller, quien en una proporción importante formó parte de los gremios. ${ }^{2}$ Como sabemos, los conciertos o contratos de aprendizaje

Fecha de recepción: 28 de marzo de 2020

Fecha de aceptación: 2 de septiembre de 2020

${ }^{1}$ La distinción entre el trabajo gremial, el trabajo en los obrajes y la producción doméstica y a domicilio ha sido ampliamente abordada por Manuel Miño Grijalva, cuyos trabajos se listan en la bibliografía. Véase en especial Miño, Obrajes, y del mismo autor, El obraje, entre otros, y SALvucci, Textiles; Mentz, Trabajo.

2 Sobre la organización gremial existe una abundante historiografía; destaco aquí sólo los trabajos de Manuel Carrera Stampa, Jorge González Angulo, 
constituyeron el mecanismo legal por medio del cual niños y jóvenes fueron entregados a maestros propietarios de talleres y también a los propietarios o administradores de los obrajes con la finalidad de que aprendieran un oficio. La base legal establecida en las ordenanzas y los contratos notariales fueron dos de los vínculos que los artesanos mantuvieron con el poder $\mathrm{y}$, al mismo tiempo, las ordenanzas y conciertos constituyeron elementos fundamentales que formalizaron la reproducción de los oficios o artes manuales a la vez que definieron con claridad la estructura jerárquica de la organización social del artesanado durante todo el periodo virreinal. ${ }^{3}$

Como he indicado en otros estudios, las corporaciones artesanales o gremios formaron parte de y se vincularon con los ayuntamientos pues ambos se encargaron de vigilar de cerca a los artesanos y de asegurar el cumplimiento de las ordenanzas, ya que mediante sus autoridades (veedores, diputados y jueces de gremios, e incluso en ciertos aspectos hasta los mayordomos a cargo de los santos patrones) podían intervenir en la vida interna del taller regulando el número de aprendices y oficiales, así como los procesos productivos y la comercialización de los artefactos en cumplimiento, sí, de las ordenanzas, pero también de las disposiciones del cabildo. El punto de convergencia de las facultades o atribuciones entre las autoridades de los cabildos y los gremios lo constituían los asuntos relativos al buen gobierno y "policía", pues ambos participaban de la obligación, de asegurar la elaboración y venta de obras de buena calidad y a precio conveniente.

$\mathrm{Al}$ respecto quiero insistir en que la organización en gremios en la Nueva España fue el resultado de un orden impuesto desde arriba, es decir, fueron las autoridades civiles las que regularon mediante ordenanzas el trabajo del artesanado dando forma

Felipe Castro y mis estudios para la ciudad de México. Véase Carrera, Los gremios; Chávez, La agonía; GonzÁlez, Artesanado; CAsTro, La extinción; Pérez Toledo, Los hijos y Trabajo.

3 Para las ordenanzas véase BARRIo, Ordenanzas. 
a sus corporaciones, pues la mayoría de los estatutos fueron presentados y aprobados precisamente por el cabildo y sólo excepcionalmente por la Audiencia, pero en todos los casos fueron aprobados por el virrey a mediados de 1540 y no fueron el resultado de la iniciativa de los propios trabajadores de los oficios avecindados en la ciudad de México. ${ }^{4}$ Entre otras cosas, en esos estatutos quedaron definidas las obligaciones de los maestros respecto de los aprendices, así como los compromisos que asumían éstos al entrar en un taller. Fundamentalmente el maestro se obligaba a recibir al aprendiz en su casa-taller para enseñarle los secretos del oficio por un tiempo determinado, asumiendo su manutención, la entrega de una muda de ropa y calzado por una sola vez, y además se comprometía a convertirse en el custodio "moral" de los aprendices que recibiera. ${ }^{5}$ Por su parte, el aprendiz debía obedecer al maestro en todo y tener buena conducta, lo que con frecuencia constituyó un espacio abierto para que los maestros se excedieran y abusaran de esta mano de obra. Asimismo, algunas ordenanzas señalaron de manera explícita la formalización del acuerdo de aprendizaje mediante un contrato escrito, así como una retribución económica que sería entregada al cumplir con el periodo establecido en el contrato.

En efecto, existe un amplio número de contratos que permite constatar la formalización del aprendizaje durante los tres siglos del dominio español; estos conciertos aportan información con la que se pueden conocer las características sociales de los niños entregados para aprender un oficio, así como las prácticas de “entrega” y los vínculos o posibles intereses que se tejieron

\footnotetext{
${ }^{4}$ Esta interpretación la hago de la lectura cuidadosa de las ordenanzas reunidas por Francisco del Barrio y Lorenzot; Barrio, Ordenanzas. La idea que sostengo es que, a diferencia a los gremios madrileños, los novohispanos no fueron el resultado de la iniciativa de los artesanos, sino que su organización fue decisión de las autoridades de la ciudad de México desde mediados del siglo Xvi. Pérez Toledo, "La trama”.

5 Sewell, Work.
} 
alrededor del proceso de aprendizaje, pues éste también supuso el establecimiento de mecanismos diversos que permitín a los maestros o propietarios de los establecimientos productivos acceder a y controlar la mano de obra, aspectos que dejo para un estudio posterior. ${ }^{6}$ Sin embargo, concuerdo con Manuel Miño y Brígida von Mentz, quienes desde posturas diferentes han señalado que el aprendizaje de los oficios (así como el control sobre la mano de obra) no siempre se realizó previa la formalización de un contrato escrito ante notario, pues con mucha frecuencia los niños y niñas aprendían el oficio en la unidad doméstica, que podía ser o no un taller en forma (como en el caso de los hijos de maestros que participaban en el trabajo dentro de la unidad familiar).

Por mi parte, considero que muchos niños y jóvenes fueron entregados a aprender un oficio en los talleres sin mediar un contrato escrito pero sí un acuerdo verbal entre las partes, práctica que con el paso del tiempo quedó establecida por "costumbre". 7 En suma, postulo que, formalizado por escrito o

${ }^{6}$ En estos momentos me encuentro realizando un estudio amplio de los conciertos de aprendizaje ubicados en el Archivo Histórico de Notarías. Brígida von Mentz en Trabajo, sujeción dedica un capítulo a estudiar a los aprendices y elabora tablas con información valiosa, aunque limitada a un periodo muy corto del siglo xvir. La autora llama la atención acerca de la necesidad de un estudio más profundo y más amplio. Mentz, Trabajo. Algunas referencias generales a la entrega de aprendices se encuentran en esta obra y también en Gonzalbo, Vivir en la Nueva España.

7 E. P. Thompson indica que: "El aprendizaje como iniciación en las habilidades adultas no se halla limitado a su expresión industrial formal. Es también el mecanismo de transmisión intergeneracional. La niña hace su aprendizaje de las obligaciones domésticas, primero con su madre (o su abuela), luego (a menudo) en calidad de sirvienta doméstica o en una granja. Como madre joven que se inicia en los misterios de la crianza de los hijos, es la aprendiza de las matronas de la comunidad. Lo mismo ocurre en los oficios en los que no hay aprendizaje reglamentado. Y con la iniciación en estas habilidades en particular llega una iniciación en la experiencia social o la sabiduría común de la comunidad. Aunque la vida social está cambiando, 
no, el aprendizaje de los oficios se verificó - al menos en la ciudad de México - en los talleres artesanales y que estuvo a cargo de un maestro, quien fungió como su custodio moral, prácticas que formaron parte de la sociabilidad tradicional y consuetudinaria de larga data de los artesanos, las cuales se ubican precisamente en el terreno de la costumbre y que contribuyeron a darle legitimidad. ${ }^{8}$

Las relaciones entre maestros oficiales y aprendices en los talleres, y por tanto las que se establecieron en los procesos de aprendizaje, no siempre fueron armoniosas; todo lo contrario, a lo largo del periodo colonial se presentaron múltiples conflictos, que podían dirimirse acudiendo a las autoridades del gremio o a otras autoridades. Los conflictos, así como las prácticas de resistencia y de negociación dentro del taller, e incluso frente a las autoridades o en las relaciones establecidas con otros actores sociales, como los comerciantes, indican precisamente la existencia de una corporación dinámica. ${ }^{9}$ Las figuras de los "rinconeros", "contraventores" y los aprendices que huían del

\footnotetext{
y aunque hay mucha movilidad, el cambio todavía no ha alcanzado ese punto en el cual se da por sentado que los horizontes de cada generación sucesiva serán diferentes; tampoco ese motor de aceleración social (y enajenación) que es la educación reglamentaria se ha interpolado todavía de modo significativo en esta transmisión generacional. Tanto las prácticas como las normas se reproducen a lo largo de las generaciones dentro del entorno lentamente diferenciador de la costumbre”. Al respecto véase Thompson, Costumbres, p. 20.

${ }^{8}$ Agulhon, "Clase obrera y sociabilidad"; Berg, La era. Véase Burke, Cultura. La importancia de las tradiciones corporativas de los artesanos franceses durante el siglo xix las estudia Sewell en Work y "Los artesanos". Por su parte, Jürgen Kocka señala que "la tradición gremial corporativa sobrevivió en Alemania durante más tiempo que en Francia e Inglaterra”. KосKA, "Los artesanos", p. 114.

${ }^{9}$ La costumbre incluso como "cultura popular" a la que se refieren E. P. Thomson y Peter Burke se entiende como un espacio de transformación y de contienda. Thompson, Tradición; Burke, Cultura. Sobre la conflictividad en el taller véase SEWELL, Work y FARge, La vida.
} 
taller nos muestran facetas diferentes que indican que aun en el ámbito de los “cuerpos cerrados" y "privativos" (celosos de sus prerrogativas) las relaciones y prácticas sociales incluyeron diversas formas de expresión de disenso y antagonismo, pero su permanencia indica también que esa sociedad corporativa tenía sus propios mecanismos de distensión del conflicto.

Es cierto que a lo largo del siglo Xvin se agudizó la crítica a los gremios y se les cuestionó por diversas razones. En relación con el aprendizaje, las objeciones se concentraron en los maestros porque los consideraban responsables de la "deficiente" enseñanza de las artes y oficios. Funcionarios reales de la metrópoli y autoridades de la capital del virreinato cuestionaron los pocos beneficios y señalaron los "grandes" inconvenientes de los gremios para el desarrollo de la industria, así como la deficiente enseñanza de los oficios. La idea de acabar con los obstáculos que la estructura corporativa y jerárquica imponía a la producción de las manufacturas la expusieron, entre otros, Pedro Rodríguez de Campomanes en el texto "Discurso sobre la educación popular de los artesanos y su fomento”, de 1775, en el que planteó una reforma educativa y disciplinaria que trascendía el ámbito estrictamente laboral; así como Gaspar Melchor de Jovellanos en 1785 en su "Informe dado a la Junta General de Comercio y Moneda”. ${ }^{10}$

En la Nueva España se replicó la crítica en el marco de los cambios y mecanismos de control que pusieron en práctica las autoridades novohispanas durante las tres últimas décadas del siglo XVIII, lo que incluyó una serie de reformas a los gremios que, entre otra cosas, trataron de impulsar la participación abierta de las mujeres en algunas de las actividades artesanales, por supuesto no sin oposición de los maestros agremiados que

10 Rodríguez, Discurso, y Jovellanos, "Informe dado a la Junta General de Comercio y Moneda sobre el libre ejercicio de las artes", en Eguiarte, Hacer ciudadanos, pp. 13-43. 
defendían sus privilegios. ${ }^{11}$ En relación con el aprendizaje en la ciudad de México, algunos miembros de la élite se expresaron abiertamente a favor de reformar a los gremios, pero sin olvidar la importancia de maestros y padres respecto de la "educación y los oficios", entre ellos el procurador general del arzobispado de México, Antonio Mier y Terán, quien en 1783 escribió un documento bastante largo en el que expuso su opinión sobre la necesidad de reformar a estas corporaciones.

La parte técnica de las artes no puede estar sujeta a un método perpetuo e invariable de enseñar y aprender los oficios porque admite variaciones continuas a proporción que se adelantan o decaen [...] Este adelantamiento o mejoría quedaría impedido si las Ordenanzas fijasen los principios de las Artes; y ninguna saldría de la infancia si se enseñasen por un mecanismo tradicionario [... pero] El método de enseñanza, la educación y aprendizaje, y la sujeción a los padres $y$ maestros deben tener útilmente su lugar en ellos: pareciendo increíble que todas las Ordenanzas de Artesanos hallan [sic] olvidado estas reglas y disposiciones tan útiles. ${ }^{12}$

Como se desprende de la exposición que realizó el procurador, la reforma propuesta se dirigía propiamente a las

${ }^{11}$ Estos aspectos se han abordado con amplitud en Pérez Toledo, Los hijos. 12 “Contra Diego Téllez Girón," 1783 en AGN, Real Audiencia Fiel Ejecutoria, Veedores, vol. 3834, exp. 110 (las cursivas son mías). Llama la atención que el procurador indique la necesidad de controlar y sujetar a los gremios a la autoridad civil eliminando la elección de sus propias autoridades; los términos en que lo expone son los siguientes: “[además] no debería permitirse como hasta aquí que los Gremios elijan veedores. Esto ha sido un abuso intolerable porque estos oficios son públicos y carecen de autoridad los cuerpos gremiales para ejecutar semejantes nombramientos que las leyes, con pulso y razón, mandan y estrechamente encargan se hagan por la justicia y Regidores [...] para que estos nombramientos recaigan en personas capases y suficientes sin dependencia ni influjo del Gremio, y con única subordinación a la Justicia y Regimiento”. 
especificaciones técnicas de la producción que establecían las ordenanzas, pues es claro que, sobre el método de enseñanza, la educación y el aprendizaje, el funcionario consideraba que los aprendices debían quedar sujetos a los padres y maestros, y más bien parece que la crítica estaba en el olvido de "estas reglas y disposiciones tan útiles”.

En contra del monopolio productivo y comercial que ejercieron los gremios actuó también la cada vez más activa participación del capital comercial, que incidió en el aumento del número de contraventores que, al margen del gremio, se dedicaron a la elaboración de mercancías. Es claro que las reformas desde arriba a los gremios y sus ordenanzas, así como la competencia provocada por el capital mercantil y por el incremento de las manufacturas “extranjeras” que llegaron a la Nueva España por la vía del contrabando o gracias a la libertad de comercio del periodo fueron minando el poder de las corporaciones de los oficios y atacaban el monopolio de producción y venta de los gremios. ${ }^{13}$ Sin embargo, respecto del proceso de aprendizaje de los oficios la crítica no se tradujo en la búsqueda de otras alternativas. En sentido estricto los maestros de los talleres continuaron a cargo de la reproducción de los oficios. Al respecto el virrey Revillagigedo recomendó que:

[...] según el estado presente de las cosas en estos reinos, que permaneciesen los gremios, reformando sus ordenanzas, o ya que no se entre en esta obra por larga y difícil, al menos hacer una general y sobre buenos principios, que mirasen únicamente a establecer la debida subordinación y orden entre maestros, oficiales y aprendices, y que estableciese algunas reglas generales de los puntos esenciales

13 "Impreso. Recopilación de noticias sobre el Comercio de contrabando con las posesiones de España en América”, en Boletín del Archivo General de la Nación, xxIx: 4 (oct., nov., dic. 1958), pp. 611-704. 
de cada clase de obras; pero sin tratar de la figura, tamaño y demás calidades. ${ }^{14}$

Había que asegurar la "debida subordinación y orden”, así como mejorar el aprendizaje de los oficios, pero más allá de recomendar la enseñanza del dibujo lineal para los plateros en la recién creada Academia de San Carlos, poca cosa se avanzó en esta materia; ${ }^{15}$ sin duda había autoridades que consideraban necesario asegurar que los artesanos se aplicaran a trabajar y se alejaran de lo que consideraban holgazanería, así como de los vicios atribuidos a la desocupación o a la "natural" propensión de estos sectores sociales a tener conductas "disipadas". ${ }^{16} \mathrm{El}$ artesano industrioso tenía su mayor atributo en la aplicación constante, en las buenas costumbres cuya responsabilidad era competencia de los maestros, quienes estaban obligados a dar buenos ejemplos a sus aprendices. Así pues, el aprendizaje del oficio y la formación de buenos súbditos y hombres virtuosos constituyó una obligación del maestro, de tal forma que incluso en el Hospicio de Pobres de la ciudad de México establecido en esos años se buscó que los pobres asilados aprendieran un oficio y el responsable de enseñar a los "clientes" del hospicio fue un maestro de oficio, por ejemplo, en zapatería. ${ }^{17}$

No me detendré aquí en las reformas a las ordenanzas ni en la reorganización de algunas corporaciones, pues esos aspectos

14 TANCK, "La abolición”, p. 315; CASTro, "La extinción”, pp. 128-129.

15 AGN, Industria y Comercio, t. 5 (véanse fojas sobre el gremio de plateros en 1789). La disposición fue reiterada por el gremio de los plateros y así quedó asentado en el Libro Becerro. Véase Libro de Autos, cabildos y elecciones del gremio de Plateros, Tiradores y Vatiogas [Batihojas] de oro, dos vols. De hecho, de acuerdo con Dorothy Tanck, en 1810 la Academia de San Carlos contaba entre sus alumnos a 99 artesanos. TANCK, "Reformas borbónicas", p. 81.

16 Sobre la utilidad del trabajo para prevenir y corregir conductas "desarregladas” como la denominada holgazanería, véanse Pérez Toledo, Los hijos y Lida y PÉrez Toledo, Trabajo; para otras latitudes Johnson, Los talleres.

$17 \mathrm{Al}$ respecto véase Arrom, Containing. 
ya se han estudiado antes. ${ }^{18}$ Lo que me interesa destacar es que ninguna de esas reformas modificó los atributos y obligaciones asignados a los maestros de los talleres artesanales. Incluso la propuesta de reglamento de 1806 elaborada por el fiscal de lo civil de la Audiencia de México, Ambrosio de Zagarzurieta, subrayó la importancia del aprendizaje de los oficios artesanales y la subordinación que se debía al maestro en su calidad custodio moral de oficiales y aprendices. ${ }^{19} \mathrm{Y}$ así quedó establecido en la reforma realizada por el virrey Iturrigaray. ${ }^{20} \mathrm{Al}$ respecto conviene destacar que entre los principio establecidos y aprobados por el virrey respecto de los gremios se indicaba:

Primero: que se fije en todos el aprendizaje, y en esto se incluya el tiempo de oficial o laborante tomándose desde los catorce años hasta los veinte y uno, y remitiéndose a las condiciones de la Escritura y convenciones particulares con los Maestros que reciban al aprendiz [...] Segundo: que el Maestro deba cuidar de la regular instrucción del aprendiz en los rudimentos cristianos, políticos y morales que convienen a su estado y de la perfecta de el en lo respectivo a su Arte, cuidando de que se acostumbre al mayor aseo y limpieza, de que no falte al trabajo, ni este exceda de las horas regulares y que sean menos de las que le toca al oficial. ${ }^{21}$

${ }_{18}$ Los bandos publicados por el virrey Miguel José de Azanza en 1799 sobre el trabajo de las mujeres y acerca de la "desnudez" de los artesanos exponen la argumentación con la que se buscó controlar a los trabajadores, pero no se ubican en el terreno de las posturas abolicionistas de las corporaciones de artesanos. AHCM, Cédulas y Reales Órdenes, vol. 2979, exp. 213, fol. 223; AGN, Impresos Oficiales, vol. 23, N1 34; véase AHCM, Artesanos Gremios, vol. 383, exp. 21. Pérez Toledo, Los hijos, véanse los capítulos 2 y 3.

${ }_{19}$ Cédula del 29 de agosto de 1806, en AGN, Comercio e Industria, vol. 18, fs. 181-182. Algunos autores escriben el apellido como Sagarzurieta véase Olmedo, "Ambrosio Sagarzurieta”, quien destaca el carácter ilustrado del funcionario peninsular que salió de Nueva España en 1822.

20 BRAcho, De los gremios, pp. 54-58.

21 Bracho, De los gremios, p. 55. 
En otras palabras, el reglamento reforzó el control y sujeción asignado a los maestros de los gremios sobre los aprendices, pero también sobre los oficiales, aunque también estableció que los maestros no podían ocuparlos "de sirviente o criado del maestro fuera del objeto del Arte que enseña”.

El tiempo en que este reglamento estuvo en vigor fue muy poco, pues los conflictos de los años subsecuentes y la legislación liberal doceañista variaron la situación legal. Sin embargo, asumo que en el siglo XIX con todo y la libertad de oficio de 1813 decretada por las Cortes españolas a escasos siete años de las reformas emprendidas por el virrey, el papel asignado al maestro o propietario de taller respecto de los aprendices y la enseñanza de los oficios mediante contrato, pero principalmente por costumbre (“de palabra”, y la palabra tenía un papel fundamental en una sociedad donde la oralidad era una de sus características), no varió sustancialmente. Así pues, con el decreto de libertad de oficio de 1813, se derogó la necesaria adscripción de los artesanos a los gremios para ejercer los oficios artesanales, pero sus dos artículos no indicaron nada respecto del sistema tradicional de entrega de niños y jóvenes para aprender un oficio. ${ }^{22}$ Aunque en los años siguientes con frecuencia se esgrimió la crítica contra

22 TANCK, "La abolición"; CASTRO, "La extinción". Postulan la abolición o la extinción de los gremios, respectivamente. En particular Dorothy Tanck señala la abolición a partir del decreto de libertad de oficio de las Cortes españolas del 8 de junio de 1813, que estableció que: "con el justo objeto de remover las trabas que hasta ahora han entorpecido el progreso de la industria decretan: I. Todos los españoles y los extranjeros avecindados, o que se avecinden en los pueblos de la Monarquía, podrán libremente establecer las fábricas o artefactos de cualquiera clase que les acomode, sin necesidad de permiso o licencia alguna, con tal de que se sujeten a las reglas de policía adoptadas o que se adopten para la salubridad de los mismos pueblos. II. También podrán ejercer libremente cualquiera industria u oficio útil sin necesidad de examen, título o incorporación a los gremios respectivos, cuyas ordenanzas se derogan en esta parte". Dublán y Lozano, Legislación mexicana, 1876, t. I, p. 412. 
el "sistema tradicionario" de aprendizaje y se hizo hincapié en la necesidad de instruir a los artesanos en los primeros rudimentos.

En otras palabras, hay que precisar que con la legislación liberal las corporaciones de artesanos recibieron un duro golpe; su tradicional vínculo con el poder se rompió, pues la elección de autoridades (veedores), así como el examen, perdieron sentido para las autoridades del ayuntamiento, aunque algunos artesanos siguieron acudiendo al mismo a presentar solicitudes para abrir un taller e, incluso, para presentar un examen a pesar de que éste dejó de ser un requisito. Como se plantea en otros trabajos, a partir de ese momento y por lo menos hasta 1843, los artesanos carecieron de un vínculo formal con el poder público y, propongo, sus organizaciones de naturaleza corporativa (ancladas en la costumbre) siguieron siendo parte de la vida cotidiana de la ciudad. Las formas de sociabilidad tradicionales propias de las funciones atribuidas a los integrantes del mundo del trabajo manufacturero en la ciudad de México permitieron la reproducción de los oficios artesanales, como se deduce de la importancia social del artesanado en 1842 y durante buena parte del siglo XIX. ${ }^{23}$

Los estudios sobre estos trabajadores para los años siguientes a la consumación de la independencia de Nueva España muestran que la legislación del periodo nacional no incorporó, ni en las discusiones ni en la práctica, algún tipo de normatividad relativa a la organización corporativa (gremial) o no del artesanado, a pesar que algunos miembros de las élites expresaron en distintos foros la necesidad de apoyar a los artesanos y estimular el "correcto" aprendizaje de los oficios. A mediados del siglo xIX, algunos políticos y varias organizaciones de trabajadores se expresaron al respecto, pero las condiciones políticas y económicas que prevalecieron durante casi medio siglo después de la independencia del país se convirtieron en obstáculos infranqueables

23 Pérez Toledo, Los hijos, capítulos 3 y 4 y Pérez Toledo, Trabajo. 
para impulsar proyectos relativos a la enseñanza de los oficios. Una breve revisión de las propuestas e iniciativas indica que la capacidad del estado en formación para hacerse cargo de formar a la mano de obra enfrentó serios obstáculos y sus logros fueron mínimos.

\section{LA REALIDAD SE IMPONE.}

LA EDUCACIÓN DEL ARTESANO ENTRE LA COSTUMBRE

Y LAS ESCUELAS DE ARTES Y OFICIOS

Una vez consumada la independencia y durante todo el siglo XIX políticos y hombres de la élite consideraron fundamental educar a la población para formar hombres útiles y buenos ciudadanos; de hecho, para acceder a los derechos políticos una condición establecida en las leyes generales (desde la constitución gaditana de 1812 hasta la constitución de 1857) fue saber leer y escribir. La instrucción elemental para niños y niñas, así como las escuelas de adultos y los gabinetes de lectura, estos últimos pensados principalmente para los artesanos porque este grupo de trabajadores fue una parte numerosa de la población de la capital mexicana, ocuparon las reflexiones de los políticos mexicanos. ${ }^{24}$ También abogaron por el fomento de la educación otros grupos sociales, como lo hicieron algunos trabajadores que, aunque tímidamente, en los primeros años del siglo se acercaron a las autoridades para solicitar que se abriera una escuela para adultos en la capital,

${ }^{24}$ Como apunta Dorothy Tanck, "En la primera república federal lo más común era ver la instrucción popular como medida para la formación cívica. Sin embargo, de vez en cuando se mencionaba la idea de que la educación, especialmente la enseñanza del dibujo, pudiera servir también como medida para preparar artesanos mejor adiestrados y así fomentar la economía. TANCK DE Estrada, "La alfabetización”, p. 111. Véanse también TANCK, $L a$ educación"; STAPLEs, Educar, "La lectura" y "Leer y escribir. 
como lo muestra la significativa representación que elaboraron varios artesanos en $1834 .{ }^{25}$

Además de las escuelas de adultos, con la ley de mayo de 1831 se estableció la creación de una escuela de artes y oficios que se buscaba fuera financiada con una parte de los 8000 pesos dedicados también a apoyar la apertura de escuelas de primeras letras en la ciudad de México. Sin embargo, la iniciativa no prosperó pues algunos consideraban que la instrucción elemental era prioritaria y el dinero asignado era insuficiente. Así, sin recursos, la escuela de artes y oficios se quedó en el papel, porque se dio prioridad a la educación elemental, pero especialmente porque durante todo 1832 y 1833 el ayuntamiento de la capital no obtuvo la autorización del gobierno general para ocupar los predios que consideraba adecuados para instalar la escuela de artes y oficios. Desde los primeros días de febrero de 1832, el ayuntamiento explicó al gobierno del Distrito que:

[...] el motivo que ha impedido a la corporación el establecimiento de Escuela de Artes ha sido la falta de local suficiente y proporcionado para tan útil objeto y no pudiéndolo realizar sin vencer esta dificultad que ha sido insuperable a pesar de los deseos y diligencias que al efecto se han emprendido, espera esta municipalidad se sirva V.E. tomar todas las providencias oportunas a fin de que el edificio del Espíritu Santo le sea entregado a esta Corporación, así por ser el más cómodo y a propósito al intento, como por no haber otro, y [éste] corresponde a las temporalidades de las Religiosas hospitalarias suprimidas. ${ }^{26}$

25 Véase "Varios individuos solicitando el restablecimiento de la Escuela Nocturna de adultos y artesanos”, año de 1834, AGN, Justicia e Instrucción Pública, vol. 18, exp. 17.

26 Véase "Sobre que se debe cumplir el establecimiento de una escuela de artes y oficios en la capital”, año de 1832, AGN, Justicia e Instrucción Pública, vol. 8, leg. 3, 1821-1860, exps. 1 y 2. Véase Memoria del Secretario, Memoria económica y Memoria o Manifiesto correspondientes a 1830,1831 y 1840. 
Las comunicaciones entre las autoridades indican que en más de un año y medio no se resolvió el problema del local, pues no se autorizó al ayuntamiento a usar el edificio del Espíritu Santo ni tampoco el de San Juan de Dios. Aunque por una parte la ley señalaba la obligación de abrir la escuela de artes y oficios y por otra tanto el gobierno general como la corporación municipal calificaron a esta escuela como necesaria y muy útil, lo cierto es que los fondos disponibles eran mínimos y según el ayuntamiento se requerían muchos gastos, en particular para dotar de alimentación y vestido a los futuros educandos, porque: “acostumbrándose esto en cualquier taller público donde los muchachos hacen su aprendizaje, lo anterior serviría de pretexto para que muchos padres se rehusaran a mandar allí a sus hijos desnudos y muertos de hambre, prefiriendo en este caso a un maestro de la calle a quienes los entregan por tres o cuatro años". 27 Testimonio que confirma que en todos estos años la reproducción de los oficios artesanales en la ciudad de México siguió a cargo de los maestros artesanos propietarios de taller o a cargo de uno, quienes seguramente establecían acuerdos de palabra con los padres que les entregaban a sus hijos para aprender un oficio por un periodo determinado.

Unos meses más tarde, se publicó la ley del 19 de diciembre de 1833 sobre instrucción, que incluyó un apartado sobre la educación de adultos, pues Valentín Gómez Farías - quien en ese momento se encontraba al frente del gobierno- estaba interesado en la creación de escuelas de artes y oficios. El artículo primero de la ley estableció que la escuela de primeras letras creada en el establecimiento de estudios ideológicos se destinaría, de forma exclusiva, “a la enseñanza de artesanos adultos, maestros,

27 Oficio del Exmo. Ayuntamiento de esta capital al Ministro de Justicia e Instrucción Pública, 1 de febrero de 1833, AGN, Justicia e Instrucción Pública, vol. 7, exp. 30, citado por Pérez Toledo, Los hijos, p. 129. 
oficiales y aprendices". Por ello las clases se impartirían por la noche y se dotaría a los artesanos de papel, tinta y plumas. ${ }^{28}$

El 1ㅇ de febrero de 1834 se inauguró una escuela nocturna para artesanos en el Hospital de Jesús y a pocos días se abrió otra en el exconvento de Belén. De acuerdo con los reglamentos de las escuelas, los alumnos aprenderían a leer y escribir, así como el dibujo aplicado a las artes y oficios. A la escuela de Belén, según el periódico El Indicador de la Federación, asistieron 196 artesanos, ${ }^{29}$ mientras que en el establecimiento del Hospital de Jesús, al parecer a cargo de José María Luis Mora, el número de adultos fue de 386 entre artesanos y jornaleros. Pero las escuelas cerraron apenas cinco meses después pues Antonio López de Santa Anna abrogó las reformas emprendidas por Valentín Gómez Farías, con lo que no es difícil suponer que los alcances de esta escuela hayan sido extremadamente reducidos si consideramos que el número aproximado de artesanos en la capital de la república se aproximaba a poco más de $13000.30 \mathrm{En}$ el caso de la escuela de adultos ubicada en el Hospital de Jesús, se sabe que el 23 de agosto un grupo de artesanos elaboró una representación por medio de la cual solicitaron, "suplicaron", al

28 Dublán y Lozano, Legislación, t. II, pp. 235-236; Pérez Toledo, Los bijos, p. 130; TANCK, "La alfabetización".

${ }^{29}$ De acuerdo con el informe, "La escuela para adultos se abrió el día $1^{\circ}$ de febrero y a proporción de que ha ido ampliándose el local, ha aumentado progresivamente el número de los alumnos que hoy llega a 196, después de haber salido algunos perfectamente instruidos en tan corto tiempo. El profesor ha ido planteando sucesivamente los ramos de enseñanza, usando en ellos de métodos breves y fáciles a virtud de los cuales se han hecho progresos rápidos. El mismo profesor da de las 6 a las 7 de la noche lecciones de dibujo a los alumnos del establecimiento", en "Segundo Establecimiento. Informe sobre el establecimiento de estudios Ideológicos y Humanidades dado por su director en consecuencia de orden circular en que lo pedía la Dirección General de Instrucción Pública", en El Indicador de la Federación Mexicana, 23 de abril de 1834, p. 380, en Mora, Obras, p. 71.

30 Sobre la población ocupada en los trabajos artesanales en la ciudad de México durante la primera mitad del siglo xix véase Pérez Toledo, Los hijos. 
presidente de la República que reconsiderara su apertura; no era la primera vez que los menestrales recurrían a estos mecanismos para dirigirse a las autoridades. La representación fue un recurso clave para dirigirse a la autoridad con la finalidad de solicitar apoyo, recursos o justicia. ${ }^{31}$

Después de los conflictos suscitados por las reformas de Valentín Gómez Farías, con el retorno de Santa Anna se inició el camino hacia el cambio de gobierno y en enero de 1837 quedó establecido el primer régimen centralista. ${ }^{32}$ Este régimen se caracterizó por una política proteccionista y en 1839 se creó la Sociedad para el Fomento de la Industria Nacional, que también abogó por una mejor educación o instrucción, pero esta organización fue abolida apenas unos años después mediante un decreto que expidió Santa Anna en septiembre de 1842.33

La década de 1840 fue importante para la organización de los artesanos y productores de manufacturas: primero, el 2 de diciembre de 1842 se creó la Junta General de la Industria Mexicana. Durante el interinato de Nicolás Bravo, se decretó la integración de lo que se denominó un gremio industrial, "cuyo órgano ejecutivo fue la Dirección General de la Industria Nacional que, al quedar a cargo de Lucas Alamán, encaminó sus esfuerzos, entre otras muchas cosas, al establecimiento de escuelas vocacionales tanto para la agricultura como para el artesanado". Y al año siguiente, el 2 de octubre de 1843, se creó la Junta de Fomento de Artesanos, organización que otorgó a éstos un espacio de interlocución formal con el poder y en el

\footnotetext{
31 "Varios individuos solicitando el restablecimiento de la Escuela Nocturna de Adultos y artesanos", año de 1834, AGN, Justicia e Instrucción Pública, vol. 18, exp. 17. Véase TANCK, "La alfabetización", pp. 119-121.

32 Costeloe, La primera y La república; VÁzQuez, "Iglesia” y Dos décadas; SORdo, El Congreso; Pérez Toledo, "Elecciones".

33 Pérez Toledo, Los hijos, pp. 117-118. Sobre la política de fomento y el proteccionismo véanse Potash, El banco; SAlvucci, Textiles y capitalismo; Thomson, "Continuidad"; Haber, "Mercados"; Thomson, "Continuidad" e Industria, principalmente pp. 17-33.
} 
que la tradición de la experiencia corporativa de los gremios se articuló con la novedad de la experiencia reciente de participación política de los trabajadores de los oficios y algunas de las prácticas propias de las mutualidades. ${ }^{34}$

En estos años, tanto la Junta de Fomento de Artesanos como el Semanario Artístico y El Aprendiz, publicaciones periódicas que fueron los órganos de expresión de las organizaciones, expusieron de forma enfática la necesidad de educar a los artesanos y proveerlos de conocimientos útiles para el desarrollo de las artes mecánicas, lo cual emprendieron ellos mismos en sus semanarios. Los discursos de esta organización artesanal muestran cómo se articuló la defensa del oficio y una postura proteccionista con el pensamiento utilitario y "dignificador" asignado al trabajo. ${ }^{35}$ Por ejemplo, la importancia atribuida al trabajo se materializó en ese año en el establecimiento de talleres de sastrería, carpintería y zapatería para los hombres, y para mujeres, de lavado y costura en la cárcel de la Ex Acordada. ${ }^{36}$

Respecto de la formación del artesanado, el 2 de octubre de 1843 se decretó la creación de los establecimientos de agricultura y artes; sobre este último se indicó que se ubicaría en la capital de República “y tendrá por objeto la enseñanza de los conocimientos que sirven de base al ejercicio de las diversas artes y oficios y la práctica de las más usuales e importantes”. Se indicaba la combinación de cursos como el dibujo lineal, las matemáticas,

${ }^{34}$ Un análisis amplio de la Junta de Fomento de Artesanos se encuentra en Pérez Toledo, Los hijos. Respecto de la participación y movilización popular en la ciudad de México durante la década de 1830 véase Pérez Toledo, "Elecciones".

35 Pérez Toledo, Trabajadores y “¿La autogestión?”.

36 "Octubre 2 de 1843. -- Orden del Ministerio de Justicia.-- Aprueba el reglamento que contiene para la cárcel de la ex-Acordada, y el contrato celebrado para el establecimiento de talleres en la misma”, en Dublán y Lozano, Legislación, t. IV, núm. 2685, p. 614. El Hospicio de Pobres y el Tecpan de Santiago también contaron con talleres de oficios. LoRenzo, El Estado, pp. 64-65. 
química y mecánica aplicada a las artes con la práctica en talleres de fundición, plaqué, "labrar y tornear metales y maderas, de hiladuría y tejeduría de lino", entre otros. ${ }^{37}$ Para el aprendizaje de los oficios se consideraba recurrir a "talleres de maestros acreditados" así como a los talleres que se establecerían en el local de la escuela. Los alumnos de la capital y los de los diversos departamentos ingresarían en calidad de aprendices y debían saber leer y escribir, así como tener nociones de aritmética.

Este decreto fue bien recibido por los artesanos de la capital que participaban en la Junta de Fomento de Artesanos; en noviembre de 1843 cuatro artesanos integrantes de esta organización se presentaron ante la Junta de la Compañía Lancasteriana para entregar un documento en el cual agradecían el establecimiento de una escuela para artesanos. ${ }^{38}$ Así, tanto la Junta como las publicaciones se convirtieron en voceros del fomento a las artes, e incluyeron argumentos en favor de una política arancelaria proteccionista en su discurso, el cual emprendió la defensa del trabajo y de la honorabilidad de los buenos "ciudadanos" dedicados a las artes mecánicas. Desde esta palestra, como los hicieron en su momento José María Luis Mora, Lucas Alamán

37 "Octubre 2 de 1843. Decreto de Gobierno. Establecimiento de escuelas de agricultura y artes”, en Dublán y Lozano, Legislación, t. IV, núm. 2684, pp. 610-614. Semanario Artístico, t. I, núm. 1 (9 feb. 1844). Pérez Toledo, Los bijos, pp. 130-131.

${ }^{38}$ La carta está firmada por Juan E. Montero y Rafael Espinoza en calidad de director y secretario, respectivamente; el 7 de noviembre de 1843 se envió a José María Tornel como presidente de la Compañía Lancasteriana, para agradecer el establecimiento de una escuela. En este documento se indicó que "Los artesanos de esta capital reunidos en junta con conocimiento del Supremo Gobierno del departamento [...] cerciorados por los papeles públicos de que la bondad de V.E. [...] para la creación de un Colegio Artístico ha llevado su protección hacia nosotros hasta proporcionarlos los primeros elementos del saber bajo los auspicios de la ilustrada y respetada Sociedad Lancasteriana [...] creemos de nuestro deber manifestar a V.E. y a la sociedad referida nuestro agradecimiento por tan decidida consideración”. AGN, Justicia e Instrucción Pública, vol. 32, exp. 62. Véase también SemanarioArtístico, 1844. 
y Lorenzo de Zavala, los artesanos se pronunciaron por la apertura de escuelas nocturnas para adultos, por el establecimiento de gabinetes de lecturas y porque hubiera escuelas de artes y oficios. Si bien la Junta de Fomento fue instalada el 27 de diciembre de 1843, para finales de 1845 la escuela de artes aún no había sido abierta, y en cambio la Junta dejó de funcionar a finales de 1846, momento extremadamente complicado para el país. ${ }^{39}$

En la década que transcurrió entre el inicio de la guerra con Estados Unidos, el restablecimiento del federalismo, la dictadura de Santa Anna y el constituyente de 1856 que abrió el espacio legal para la formación de asociaciones mutualistas en México, ${ }^{40}$ no hubo una discusión profunda acerca de los problemas relativos a la enseñanza de los oficios, aunque sí se legisló en favor del establecimiento de la libertad de trabajo y de educación. ${ }^{41} \mathrm{Y}$ lo más importante fue que en ese año Ignacio Comonfort impulsó la apertura de la Escuela de Artes y Oficios mediante el decreto del 18 de abril de 1856, que retomó las disposiciones de octubre

39 Pérez Toledo, Los hijos, p. 118 y siguientes. De acuerdo con Anne Staples, "las esperanzas chocaron con una realidad conflictiva, la falta de recursos y estabilidad política, las amenazas de invasión externa y de rebeliones internas", elementos que no permitieron que este periodo de muchas iniciativas y proyectos rindiera los frutos educativos esperados. STAPLES, "Leer", p. 175.

40 Sobre este tema, durante el periodo de 1853 y hasta las organizaciones de trabajadores de nuevo tipo en la ciudad de México, véanse los trabajos de Illades, Hacia; Trujillo, Operarios; Teitelbaum, “Asociación”; Gutiérrez, El mundo; Orduña, "Ensayo"; Lear, "Del mutualismo” y Workers; Ramos, Industrialización. Existe una amplia bibliografía sobre el tema para otras latitudes; para los casos inglés, francés y alemán véanse Hobsbawm, El mundo; Thompson, Tradición; Sewell, "Los artesanos”; KоскA, "Los artesanos”; algunos estudios sobre países de América Latina son: BeretTA, Inmigración; LoAizA, Sociabilidad; Sowell, Artesanos.

${ }^{41}$ Durante las sesiones del Congreso de 1856, Ponciano Arriaga se pronunció por proteger la producción artesanal, pero otros, como Guillermo Prieto, estuvieron en desacuerdo con aquello que limitara la liberad de industria y de trabajo. Bracho, De los gremios, pp. 93-99. 
de $1843 .{ }^{42}$ Sin embargo, los serios conflictos políticos y militares no brindaron condiciones adecuadas para que el antiguo establecimiento de San Lorenzo en su calidad de Escuela de Artes y Oficios pudiera impulsar la formación de los trabajadores en los oficios o artes mecánicas tradicionales y emergentes. ${ }^{43}$ En ese contexto, al iniciarse el emblemático año de 1857 se abrió la Escuela que, con fondos públicos y bajo el manto del gobierno, intentaba contribuir a la formación del artesanado, pero las buenas intenciones tropezaron de nuevo con la realidad, por lo que propiamente el funcionamiento regular y continuado de la escuela de oficios para hombres inició más tarde, cuando la estabilidad política permitió la apertura de algunos talleres. ${ }^{44}$ Pues según se deduce de la nota de El Siglo Diez y Nueve, aun antes de 1863 la escuela había dejado de funcionar:

\footnotetext{
42 "Abril 18 de 1856. Decreto de Gobierno. Se establece una Escuela de Artes y Oficios”, en Dublán y Lozano, Legislación, t. VIII, núm. 4680, pp. 149150. En el mes de octubre se publicó el reglamento de la Escuela de Artes y Oficios, también denominada Escuela Industrial. Véase “Octubre 10 de 1856. Reglamento expedido para el nombramiento de alumnos de la escuela de Artes y Oficios", en Dublán y Lozano, Legislación, t. VIII, núm. 4807, pp. 266-269.

43 Rivera, México, p. 68.

44 Además de los textos generales de historia de la educación que se refieren de manera general a la Escuela Nacional de Artes y Oficios para hombres de la ciudad de México, esta institución se ha estudiado con cierta amplitud a partir de la documentación que produjo y que resguarda el archivo de la EsIME. Se trata de tesis de licenciatura, maestría y, la más reciente, una de doctorado cuyo abordaje está dedicada principalmente a la institución. Véanse Sánchez Meneses, "Escuela Nacional”; MÁrquez, "La Escuela”, y recientemente López, "Aprendiendo". Para el caso de Zacatecas véase AmAro, La educación. Por supuesto, los estudios sobre la historia de la educación que analizan el periodo comprendido entre la República Restaurada y el porfiriato aportan información importante. Véanse González, Historia moderna de México. El porfiriato; Meneses Morales, Tendencias; Bazant, Historia y "La capacitación"; CHAOUL, Entre la esperanza, entre otros.
} 
Recordamos que la Escuela de Artes y Oficios fue cerrada por la reacción, y despedidos todos sus alumnos, entre los que había algunos enviados por los Estados conforme a lo dispuesto por el gobierno general. Estos jóvenes interrumpieron su carrera, tuvieron mucho que sufrir, y sería justo que, si es posible, fueran ahora admitidos de preferencia en la Escuela de Agricultura, ya que de pronto no es posible restaurar la Escuela de Artes y Oficios. ${ }^{45}$

La guerra civil entre liberales y conservadores (1858-1861), la intervención francesa en 1862 y el Segundo Imperio (18641867) no ofrecieron condiciones para impulsar proyectos para la formación de trabajadores. Con el retorno de Benito Juárez a la capital en julio de 1867 se inició una etapa de reorganización del país, si bien es cierto que el proceso de centralización y estabilidad no se alcanzaría sino casi una década después. En materia educativa se publicó primero la Ley Orgánica de Instrucción Pública en el Distrito Federal el 2 de diciembre y en el siguiente año se decretó el reglamento en el que se anotaron las ideas acerca de la educación de adultos, a los cuales se les enseñarían "rudimentos de física y química, aplicados a las artes, dibujo lineal”, entre otras cosas. Dos años después, la Ley Orgánica de Instrucción Pública de 1869 y su reglamento ${ }^{46}$ establecieron prácticamente las mismas disposiciones respecto de la Escuela de Artes y Oficios que la ley de 1867. De acuerdo con estas disposiciones, en la escuela se enseñaría durante un periodo de cinco años y se buscaría formar a los niños mayores

${ }^{45}$ El Siglo Diez y Nueve (13 feb. 1863), p. 4.

46 Véanse "Diciembre 2 de 1867. Ministerio de Justicia. - Ley Orgánica de Instrucción Pública en el Distrito Federal"; "Enero 24 de 1868. Reglamento de la Ley Orgánica de Instrucción Pública”; "15 de Mayo de 1869.-Ley Orgánica de Instrucción Pública en el Distrito Federal”, en Dublán y Lozano, Legislación, t. X, núm. 6182, pp. 193-205; núm. 6240, pp. 242-243 y núm. 6594, pp. 591-601, respectivamente. Sobre la importancia de estas leyes véanse Pérez Toledo, "La educación"; Meneses Morales, Tendencias; VÁzquez, Nacionalismo y educación; Bermúdez, "Una población”. 
de 16 años en los oficios, así como en los conocimientos que se consideraron importantes y necesarios para hacer que este tipo de educación secundaria contribuyera a formar ciudadanos aptos para el trabajo. Los alumnos tenían como requisito de ingreso haber concluido la instrucción elemental, pues debían saber leer y escribir, así como las primeras nociones aritméticas adquiridas en el nivel de primaria. Las materias que cursarían en la escuela serían:

Español, francés e inglés, aritmética, álgebra, geometría, trigonometría rectilínea, física y nociones de mecánica, química general, invenciones industriales, práctica de artes y oficios en los talleres que se establecieren conforme a los reglamentos que se dicten. ${ }^{47}$

Se trató de un programa ambicioso que incluyó una amplia formación teórica que en principio tendría el importante complemento de la práctica en artes y oficios en talleres. La escuela de artes y oficios para hombres empezó a funcionar después de la expedición de su nuevo reglamento, que partió de las disposiciones reglamentarias de 1856 y de la instalación de la Junta de Profesores, y de la realización de algunas reparaciones para acondicionar el local del edificio del exconvento de San Lorenzo que fue cedido por decreto a la escuela. Algunos autores indican que en su inicio hubo 100 alumnos, de entre los cuales algunos eran becados, pero también hay diversos testimonios que indican que no contó desde su apertura con los talleres para apoyar la formación práctica. ${ }^{48}$ De hecho, la mayoría de los autores

47 Véase "Diciembre 2 de 1867. Ministerio de Justicia. - Ley Orgánica de Instrucción Pública en el Distrito Federal”, en Dublán y Lozano, Legislación, t. X, núm. 6182, p. 196.

48 Rivera, México, indica que "En 1867 fue expedida una ley para que en la Escuela de Artes y Oficios se establecieran los talleres necesarios en que los alumnos practicaran, poniéndolos al tanto de los adelantos y diversas aplicaciones alcanzadas, sin por esto desatender los conocimientos científicos 
coincide en que durante la década de 1870 la escuela enfrentó serios problemas por la falta de materiales y herramientas, así como porque se le asignaron recursos limitados que obstaculizaron la inmediata apertura de todos los talleres señalados en las leyes. ${ }^{49}$

Así, al iniciar la década de 1870, los discursos en la prensa y las buenas intenciones expresadas en las leyes que plantearon la necesidad de formar hombres para el trabajo en los diversos oficios artesanales y mecánicos de la época, y que consideraban también necesario moralizarlos para que tuvieran un mejor destino que el que conducía a la pobreza y la criminalidad, tuvieron en la práctica obstáculos diversos, principalmente de orden económico, que impactaron negativamente para avanzar en la formación de los aprendices como oficiales o maestros. En este contexto, los alcances de la Escuela de Artes y Oficios respecto de la reproducción de la mano de obra, no sólo como artesanos calificados sino como técnicos, fueron extremadamente limitados. Y ésa fue también la situación de los otros establecimientos en los que se buscó formar o corregir mediante el trabajo instalando talleres para ocupar y disciplinar a los individuos recluidos en el Hospicio de Pobres o bien en el Tecpan de Santiago, que en 1871 se denominó Escuela Municipal de Artes y Oficios. ${ }^{50}$

más indispensables para la aplicación de las artes; al reestablecerse la Escuela fueron abiertas solamente las clases teóricas establecidas por la ley y no los talleres, cuya creación, aunque costosa, era indispensable”, p. 61.

49 Sobre las difíciles condiciones en las que funcionó la escuela en estos años Carlos Illades indica que "Durante la década siguiente [1870] la institución tuvo una decadencia relativa. Escaseaban útiles, herramientas e insumos y el inmueble estaba en malas condiciones”. Véase Illades, Hacia, p. 135, también pp. 129-144; SÁNCHEZ, "Escuela”; MÁrquez, "La Escuela”; López, "Aprendiendo".

50 Lorenzo, El Estado, pp. 66, 80, 168-170; Lorenzo, “Los contratos”, p. 146 y siguientes. La autora indica que “entre 1877 y 1905, en el Técpan funcionaron los talleres de sastrería, carpintería, herrería, zapatería, tejeduría e impresión. En el Hospicio de Pobres, en cambio, se suprimieron los talleres 
En todos los casos, así como en la Escuela de Artes y Oficios para Mujeres creada también en 1871, el mayor problema de los establecimientos de este tipo lo constituyeron por una parte la falta de talleres y una inadecuada habilitación, y por la otra, la falta de profesores capacitados para la enseñanza de los oficios, a lo que se sumó que la mayor parte del tiempo de la enseñanza se dedicó a la formación teórica general más que a la enseñanza teórica y principalmente a la práctica de un oficio determinado. En estas condiciones, como señala María Dolores Lorenzo para el caso de los talleres de la beneficencia, estos establecimientos con frecuencia dependieron de maestros propietarios de taller que mediante contrato se encargaron de los talleres o recibieron una mano de obra en sus locales, en los que "los maestros conservaron su autoridad respecto de los conocimientos de sus alumnos y con ello preservaron, aunque en otro ámbito, su lugar en la jerarquía del taller artesanal". ${ }^{1}$

Ahora bien, es importante subrayar que la reglamentación en la materia es producto de la emergencia del estado liberal, y su lectura muestra que, si bien las escuelas procuraban formar y disciplinar a la mano de obra, por otra parte reprodujeron algunos elementos de la estructura propia de la organización social del trabajo artesanal de viejo cuño, es decir, la tradicional división entre aprendices, oficiales y maestros, y estos últimos eran los que debían transmitir los secretos del oficio a los oficiales y aprendices. No obstante, hay que hacer énfasis en que para este momento efectivamente el proceso de formación de artesanos en todos estos establecimientos adquirió un carácter público que no se puede perder de vista, pues en el caso de las escuelas de artes y oficios las encabezó el gobierno federal a través primero

de carpintería y zapatería de la sección de niños, aunque se mantuvieron los talleres de imprenta y tejeduría”, p. 147.

51 Lorenzo, "Los contratos", p. 157. La Escuela de Artes y Oficios para Mujeres la estudian Aquino, "Cultivando"; López, "Aprendiendo"; M. BAZANT, Historia de la educación. 
del Ministerio de Fomento (1856) y más tarde del Ministerio de Justicia e Instrucción Pública (1867), hasta que la Secretaría de Justicia e Instrucción Pública y Bellas Artes asumió su administración y control. ${ }^{2}$

También hay que considerar que si bien el proceso de secularización es innegable, la capacidad de los gobiernos para efectivamente incidir en la reproducción de los oficios fue mínima, ya que en la ciudad de México ésta siguió fundamentalmente en manos de los maestros de los talleres. ${ }^{53} \mathrm{Si}$ bien es cierto que

52 En el periodo se observa una clara y creciente tendencia hacia la intervención estatal en la instrucción de la niñez y se distingue perfectamente durante el porfiriato, pero tiene su antecedente en las Leyes de Instrucción de 1867 y 1869 que corresponden al periodo de la "República Restaurada". Los frutos en materia educativa del "Liberalismo Triunfante", como lo llama Luis González, fueron realmente importantes pues pusieron nuevamente en discusión el problema de la vigilancia del Estado sobre la instrucción. Problemática que frente la libertad de enseñanza había provocado acalorados debates desde el propio Congreso de 1856. El artículo tercero de la Constitución de 1857 estipuló la "libertad de enseñanza" debido a la abierta oposición hacia la intervención del Estado. Sin embargo, para 1867 no era posible que los liberales pudieran confiar en una libertad irrestricta como la preconizada por el artículo tercero constitucional. De acuerdo con los liberales, la educación era la herramienta para la creación de hombres nuevos que, lejos de la influencia de la Iglesia, fueran capaces de habilitar el progreso y la modernidad. GuERRA, México. De ahí la importancia de la formación para el trabajo y de que la federación se hiciera cargo de las escuelas municipales de la ciudad de México en 1896. Pérez Toledo, "La educación elemental".

${ }^{53}$ Comparto la idea de Silvia Arrom acerca de los límites del estado liberal para hacerse cargo de la beneficencia y la importancia de las instancias particulares (incluidas las asociaciones católicas) para atender a esta población. Véase Arrom, Containing. Aunque sobre las escuelas de artes y oficios Carlos Illades señala que: "Su historia muestra la transferencia del aprendizaje de los oficios del gremio a la escuela pública, situación enmarcada en el proceso más amplio de cesión de funciones y privilegios corporativos en favor del Estado en construcción”. Illades, Hacia, p. 141; conviene precisar que en la práctica la transferencia efectiva no se verificó durante todo el siglo XIx. Los límites del estado liberal para echar a andar establecimientos de artes y oficios eficaces no le permitieron desplazar a los maestros de los pequeños 
a la escuela pública (aunque también a algunas sostenidas con fondos particulares) se le asignó un sitio en la reproducción y producción de viejos oficios y de los oficios emergentes, el proceso fue extremadamente lento y de alcances bastante limitados incluso durante las décadas de mayor estabilidad política y de mayor asignación de presupuesto a la educación y a las escuelas de artes y oficios, periodo que se inicia en la década de 1880 y llega hasta el inicio de la revolución mexicana. ${ }^{54}$ Así, durante las tres décadas siguientes, periodo en el que funcionaron las escuelas de artes y oficios para hombres y para mujeres en la ciudad de México, difícilmente estos establecimientos y otros de su tipo pudieron reemplazar al maestro del pequeño taller en la formación de la mayoría de los artesanos. Éste, el maestro de los múltiples talleres de la capital, continuó a cargo de la formación de la mayor parte de los artesanos, aunque en situaciones de precariedad y seguramente con muchas deficiencias, contribuyendo a su parcial descalificación. Y no podía ser de otra manera debido a los reducidos logros de la escuela respecto de la formación de un número importante de artesanos. Veamos.

La ciudad de México contó desde el periodo virreinal con un número importante de trabajadores dedicados a la producción artesanal, así como con un buen número de pequeños talleres en los que se producía una amplia gama de productos con los que se abastecía el mercado de la capital. Como lo han mostrado diversos especialistas, la producción textil ocupó un sitio importante tanto por el número de talleres como por el de artesanos ocupados en las distintas fases de esta producción. Un segundo lugar

\footnotetext{
talleres en la reproducción de los oficios, planteamiento sobre el que volveré más adelante.

${ }^{54}$ Un análisis sobre la evolución del presupuesto federal asignado a la educación se encuentra en Pérez Toledo, "La educación”, véase el cuadro 1, y "Cuenta del Tesoro Federal”, en AGN, Hacienda; véase también GonzÁlez, Historia moderna de México. El Porfiriato; M. Bazant, Historia de la educación y "La capacitación"; CHAOUL, Entre la esperanza.
} 
lo tuvieron los individuos y establecimientos vinculados con el trabajo de la madera, y un tercero los que trabajaron el cuero, principalmente, zapateros. Pero además de éstos hay que considerar a todos los que se dedicaron al trabajo de los metales preciosos y no preciosos, así como a los que se dedicaron a trabajar la pólvora, el tabaco y al procesamiento de ciertos alimentos. ${ }^{55}$

Durante todo el siglo xix la ciudad de México mantuvo un número importante de pequeños talleres cuyas características por su tamaño, número de trabajadores, su escasa mecanización y división del trabajo podemos considerar propios de la manufactura de tipo artesanal. El lento proceso de industrialización, como también lo han mostrado varios especialistas, no inició con paso firme sino a mediados de la década de 1860 , y en el caso de la producción de textiles y papel los principales centros fabriles se ubicaron fundamentalmente fuera del espacio comprendido por la ciudad de México. ${ }^{56}$

Por supuesto que durante las décadas que siguieron a la independencia se verificaron cambios, ya que después de un largo periodo de estancamiento económico, fue precisamente a finales de la década de 1860 cuando inició un lento proceso de crecimiento económico, claramente definido a partir de 1880, el cual se caracterizó por la atracción de capitales y una mayor inversión en ciertas áreas de la producción manufacturera e industrial, proceso que estuvo vinculado con los

55 Se calcula que a finales del siglo xviII había por lo menos 1896 establecimientos productivos distribuidos en todo el espacio urbano, aunque buena parte se ubicaban en la parte central de la ciudad. Véase Pérez Toledo, Los hijos, p. 165 y Trabajadores, pp. 41-44.

56 Sobre las fábricas ubicadas en el Valle de México y otros establecimientos de una dimensión mayor al pequeño taller artesanal en la ciudad de México véase Trujillo, Operarios; Ramos, Industrialización. Sobre la diversidad laboral incluido el trabajo en las manufacturas, véanse Porter, Mujeres; BARbosa, El trabajo. Entre los estudios que discuten acerca del lento proceso de industrialización véanse Haber, "Mercados"; Thomson, "Continuidad"; Lear, Workers; Gómez-Galvarriato, "Fragilidad” e Industria. 
cambios en los transportes y las innovaciones tecnológicas. Este proceso corrió paralelo al de centralización política y fortalecimiento del régimen porfirista, aunque el crecimiento económico y la industrialización fue desigual en el país. Por su parte, en términos sociales se verificó un aumento de población que, por supuesto, incidió en la transformación de la estructura social, así como en la transformación de ciertos oficios, pero considero necesario insistir (como lo han señalado antes otros especialistas) en que en la ciudad de México los pequeños talleres artesanales continuaron predominando en el espacio urbano durante buena parte del siglo xix en contraste con los establecimientos productores de manufacturas de mayor tamaño.

Para calibrar la permanencia de este rasgo general importa recordar en primer término los datos relativos a la evolución de los talleres artesanales en la ciudad de México entre 1842 y 1865 (véase la tabla 1). Estos números muestran que entre uno y otro momento el número de establecimientos se incrementó en $7.4 \%$, proporción que, si bien puede parecer poco significativa, indica que, a pesar de las difíciles condiciones económicas, así como de la inestabilidad política y los conflictos bélicos, la estructura productiva en manos del pequeño taller no fue desplazada en todos estos años. Por otra parte, también indican de forma indirecta que la reproducción de los oficios debió verificarse sin duda en estos establecimientos, pues como vimos, durante todo ese periodo no se pudo contar con las escuelas de artes y oficios.

Como se puede observar en la tabla 1, entre uno y otro año se ve claramente la reducción de establecimientos dedicados a la producción textil, lo que se podría explicar por la competencia de la producción de los centros de mayor tamaño y las fábricas que fueron adquiriendo mayor importancia en los siguientes años. Pero en otros rubros se muestra por un lado 
un incremento, así como la emergencia de talleres de oficios nuevos. ${ }^{57}$

\section{Tabla 1}

CAMBIOS EN LA COMPOSICIÓN DE LA ESTRUCTURA

PRODUCTIVA. TALLERES EN LA CIUDAD DE MÉXICO, 1842-1865

\begin{tabular}{|lrrrr|}
\hline Rama productiva & 1842 & $\%$ & 1865 & $\%$ \\
\hline Madera & 278 & 18.0 & 344 & 20.70 \\
Textil & 381 & 24.6 & 297 & 17.87 \\
Metales no preciosos & 203 & 13.1 & 257 & 15.46 \\
Cuero y pieles & 230 & 14.9 & 179 & 5.39 \\
Alimentos & 61 & 3.9 & 166 & 9.99 \\
Barbería y peluquerías & 118 & 7.6 & 117 & 3.52 \\
Metales preciosos & 55 & 3.6 & 73 & 4.39 \\
Imprenta & 45 & 2.9 & 58 & 1.74 \\
Cera y velas & 77 & 5.0 & 46 & 2.77 \\
Pintura & 37 & 2.4 & 34 & 2.05 \\
Relojería & 14 & 0.9 & 27 & 1.62 \\
Fotografía & 0 & 0.0 & 23 & 1.38 \\
Cerámica y vidrio & 28 & 1.8 & 21 & 1.26 \\
Varios & 20 & 1.3 & 20 & 1.20 \\
Total & 1547 & 100 & 1662 & 100.00 \\
\hline
\end{tabular}

Fuente: Pérez Toledo, Trabajadores, espacio, cuadro 12, p. 81.

Si bien es cierto que no se ha realizado un análisis acerca del número de talleres en la ciudad de México para la década de 1880, por ejemplo a partir del padrón realizado en la capital en 1882 que ha trabajado María Dolores Morales, se puede afirmar que para ese año la capital tenía, como en las décadas previas, un número

${ }^{57}$ Los datos de esta tabla corrigen al alza las cifras señaladas antes por otros autores a partir del mismo documento debido a que estos datos incluyen el total de los establecimientos registrados en el Padrón de Establecimientos de 1865. Una explicación más amplia al respecto se encuentra en Pérez Toledo, Trabajadores, pp. 78-86. 
importante de pequeños talleres artesanales. ${ }^{58}$ Asimismo, John Lear indica con razón que la transformación de la producción manufacturera es clara de 1880 en adelante, pero que todavía los talleres artesanales ocupaban al $37 \%$ de la fuerza de trabajo en 1895 y al $33 \%$ en 1910 , con todo y que, como indiqué antes, en ese periodo también se establecieron manufacturas de tamaño intermedio, así como fábricas dedicadas principalmente a la producción textil y de tabaco, como la fábrica del Buen Tono. ${ }^{59}$

Ahora bien, si por otra parte evaluamos la información y los datos disponibles relativos a la Escuela de Artes y Oficios para Hombres, podemos verificar los alcances de esta institución en la reproducción de los oficios, en la formación del artesanado de la ciudad de México. De acuerdo con los datos que ofrecen diversas fuentes, sabemos que hacia la década de 1880 esta escuela tuvo mejores condiciones y que en 1898 se reformó su plan de estudios. ${ }^{60} \mathrm{El}$ ingeniero y arquitecto Manuel Francisco Álvarez, uno de sus directores, que estuvo al frente de la escuela por varias décadas, desde 1877 hasta 1905, en distintos espacios y de forma reiterada destacó la importancia de la escuela y sus

58 María Dolores Morales elaboró una base de datos con la información contenida en este censo, y un trabajo detallado de la fuente sin duda puede arrojar mayor información para caracterizar la estructura productiva de la ciudad de México con mayor precisión. Véase Morales, "El padrón”. A pesar de que este análisis está pendiente, el trabajo de captura, sistematización y análisis realizado hasta ahora por la investigadora sustenta su afirmación acerca de que en 1882 la ciudad de México contaba con muchos pequeños establecimientos o talleres con un número reducido de trabajadores, algunos de los cuales se ubicaban en las viviendas o en la propia unidad doméstica. Entrevista a María Dolores Morales, 16 de marzo de 2020.

59 Tan sólo en el rubro textil, en 1865 aparecen 42 talleres con un reducido número de telares. Trujillo, Operarios, p. 43. Lear, Workers, pp. 58-73, y especialmente p. 64. Para sopesar la importancia de la producción textil en el Valle de México y en la capital a finales del siglo xix y principios del xx véase Ramos, Industrialización, y PORTER, Mujeres.

${ }^{60}$ Por ejemplo, en el periodo se incrementó el presupuesto. Véase GonZález, "Presupuesto de la Federación", en Estadísticas. 
aportes. ${ }^{61}$ Con frecuencia informó acerca del incremento de los alumnos inscritos y de las mejoras materiales del establecimiento o de la modificación de los planes de estudio con la finalidad de promover la formación técnica o industrial, como se le denominó en esos años. ${ }^{62}$ Sin embargo, el director reconoció en su momento que existía un gran problema de deserción y que era necesario reducir el periodo de estudios de cinco a tres años. Un documento elaborado por Álvarez en 1902 destaca por su reseña histórica acerca de los primeros años de la escuela y en él narra las dificultades que enfrentó, entre ellas la falta de materiales y la deficiente enseñanza práctica, pero de algunos de sus planteamientos se puede dilucidar el papel todavía asignado al taller artesanal en la formación de los artesanos. Así, en las conclusiones del "Proyecto de organización de la enseñanza técnica industrial en México”, Álvarez afirmó:

De todo lo expuesto se deducen las siguientes conclusiones que me permito exponer para la organización técnica industrial en México: $1^{\circ}$. Deben los particulares, las sociedades, los municipios, Gobierno en general y de los estados, fomentar el desarrollo de la industria fabril y manufacturera, protegiendo la instalación de fábricas que aumenten y abaraten la producción y principalmente las pequeñas

${ }^{61}$ La Escuela de Artes y Oficios para Hombres estuvo a cargo de Miguel Hurtado de diciembre de 1867 a enero de 1877, del ingeniero Manuel Francisco Álvarez de enero de 1877 a julio de 1905, a partir de ese año estuvo al frente el ingeniero Gonzalo Garita (agosto de 1905 a junio de 1911), a mediados de ese año lo reemplazó José A. Bonilla (junio de 1911 a abril de 1912), y durante los años más complicados por la guerra, Carlos M. Lazo (mayo de 1912 a agosto de 1914) y Enrique M. Ibáñez (de septiembre de 1914 a marzo de 1915), quienes prácticamente se ocuparon de cerrar el establecimiento. La historia de la Institución la encontramos en Márquez, "La Escuela”; SÁnchez, "Escuela”, y López, “Aprendiendo".

${ }^{62}$ Eguiarte, Hacer ciudadanos, p. 161-185. 
industrias que requieran más inmediatamente el trabajo manual como medio de proporcionar el aprendizaje de las artes y los oficios. ${ }^{63}$

En efecto, en los 48 años que funcionó la escuela de artes y oficios, si bien los gobiernos de Juárez, Lerdo de Tejada y Porfirio Díaz la apoyaron mediante un incremento modesto del presupuesto para dotar de mejores condiciones a la escuela con el objetivo de formar a un número mayor de alumnos, lo cierto es que durante más de la mitad de esos años la enseñanza teórica privó sobre la práctica de los oficios en los talleres, a pesar de las tres importantes reformas al plan de estudios. Por otra parte, con frecuencia los talleres carecieron de las herramientas necesarias para practicar los diferentes oficios, por lo que debían rotar a los alumnos antes de dedicarse a un oficio de su elección.

El gran problema de la escuela es lo que en términos actuales denominamos baja eficiencia terminal, pues todo indica que los alumnos desertaban para irse a trabajar en un taller con la finalidad de obtener un ingreso de forma más inmediata y no hasta concluir los cinco años de estudio. La precaria situación económica de la mayoría de la población urbana que formaba parte de las clases populares hacía que difícilmente pudieran esperar a concluir sus estudios para colocarse en un trabajo que les permitiera disponer de recursos económicos. ${ }^{64}$ En estas

${ }^{63}$ Manuel F. Álvarez, "Proyecto de organización de la enseñanza técnica industrial en México", agosto 4 de 1902, en Eguiarte, Hacer ciudadanos, p. 182. El proyecto diferencia entre la educación para la formación de los oficios, incluida la impartida en la Escuela de Artes y Oficios, así como la de otros establecimientos de beneficencia y corrección, respecto de la educación de las "escuelas científicas de industria".

${ }^{64}$ De acuerdo con Rivera: “Actualmente [a principios de la década de 1880] se recibe en la Escuela de Artes y Oficios instrucción que ya se puede calificar de extensa; se aprende el dibujo natural y de ornato, el modelado y la talla en madera, el dibujo lineal y de máquinas, la alfarería, carpintería, cantería, herrería, tornería, tipografía, litografía, fotografía, fotolitografía y galvanoplastia; además hay cátedras de aritmética, álgebra, geometría y 
circunstancias, a pesar de que los registros de inscripciones de alumnos localizados en el archivo de la escuela, así como los obtenidos a partir de los informes que se muestran en la tabla 2, indican un aumento más o menos constante de la inscripción de jóvenes, lo cierto es que las generaciones de egresados más exitosas estuvieron integradas por un número extremadamente reducido de alumnos e incluso destaca que hubo años en los que no hubo ningún egresado.

Tabla 2

ESCUELA NACIONAL DE ARTES Y OFICIOS PARA HOMBRES

(1872-1915)

\begin{tabular}{|c|c|c|c|c|}
\hline Año & $\begin{array}{c}\text { Número de } \\
\text { inscripciones }\end{array}$ & $\begin{array}{c}\text { Asistencia } \\
\text { media }\end{array}$ & Becados & $\begin{array}{c}\text { Número de } \\
\text { egresados }\end{array}$ \\
\hline 1872 & 78 & s/i & s/i & s/i \\
1873 & 122 & s/i & s/i & s/i \\
1874 & 107 & s/i & 29 & s/i \\
1875 & 209 & s/i & 26 & s/i \\
1876 & s/i & s/i & s/i & s/i \\
1877 & s/i & s/i & s/i & s/i \\
1878 & 371 & 150 & 33 & 6 \\
1879 & 305 & 149 & 12 & s/i \\
1880 & s/i & s/i & s/i & s/i \\
1881 & 441 & 200 & 47 & 2 \\
1882 & 304 & 300 & 49 & 2 \\
1883 & s/i & s/i & s/i & s/i \\
1884 & 315 & 130 & 36 & s/i \\
1885 & 376 & 150 & 26 & s/i
\end{tabular}

trigonometría, gramática castellana, geografía y escritura, la enseñanza de la física y las nociones de mecánica, la química general y la industrial; para estas clases hay los preparadores y los mozos correspondientes; se enseña además música y gimnasia. Los empleados que cuidan inmediatamente del establecimiento son: el director, el prefecto bibliotecario, el mayordomo tesorero, un guarda-almacenes y proveedor de talleres”. México, p. 61. Los planes de estudio, sus características y las modificaciones se pueden ver con mayor detalle en SÁNCHEz, "Escuela”. 
Tabla 2

ESCUELA NACIONAL DE ARTES Y OFICIOS PARA HOMBRES (1872-1915) (concluye)

\begin{tabular}{|c|c|c|c|c|}
\hline$A \tilde{n} o$ & $\begin{array}{l}\text { Número de } \\
\text { inscripciones }\end{array}$ & $\begin{array}{l}\text { Asistencia } \\
\text { media }\end{array}$ & Becados & $\begin{array}{c}\text { Número de } \\
\text { egresados }\end{array}$ \\
\hline 1886 & 357 & 170 & 14 & $6 *$ \\
\hline 1887 & 390 & 160 & 8 & $s / i$ \\
\hline 1888 & 289 & 140 & 13 & $\mathrm{~s} / \mathrm{i}$ \\
\hline 1889 & 199 & 115 & $\mathrm{~s} / \mathrm{i}$ & s/i \\
\hline $1890 * *$ & 262 & 150 & $\mathrm{~s} / \mathrm{i}$ & 0 \\
\hline $1891 \%$ & 322 & 170 & $\mathrm{~s} / \mathrm{i}$ & $2 * * *$ \\
\hline 1892 & 298 & 180 & $4 *$ & 0 \\
\hline 1893 & 279 & 160 & $\mathrm{~s} / \mathrm{i}$ & 1 \\
\hline 1894 & 301 & 170 & $1 *$ & 0 \\
\hline 1895 & 255 & 140 & $2 *$ & 1 \\
\hline 1896 & 274 & 150 & s/i & 0 \\
\hline 1897 & 350 & 160 & $\mathrm{~s} / \mathrm{i}$ & 1 \\
\hline 1898 & 440 & 216 & $\mathrm{~s} / \mathrm{i}$ & 1 \\
\hline 1899 & 199 & 115 & $\mathrm{~s} / \mathrm{i}$ & 0 \\
\hline 1900 & 230 & 166 & $\mathrm{~s} / \mathrm{i}$ & 0 \\
\hline 1901 & 221 & 110 & 2 & 2 \\
\hline 1902 & 379 & 185 & 6 & 9 \\
\hline 1903 & 398 & 166 & s/i & 6 \\
\hline 1904 & 290 & 144 & 12 & 8 \\
\hline $1905^{*}$ & 360 & 161 & 12 & $3 \%$ \\
\hline 1906 & $\mathrm{~S} / \mathrm{I}$ & $\mathrm{S} / \mathrm{I}$ & $s / i$ & 8 \\
\hline 1907 & 286 & 132 & 15 & 3 \\
\hline 1908 & 250 & 146 & 11 & 14 \\
\hline $\begin{array}{l}1909- \\
1910\end{array}$ & 303 & 188 & 7 & 10 \\
\hline 1911 & 274 & 156 & 14 & 3 \\
\hline 1912 & 312 & 166 & 17 & 3 \\
\hline 1913 & 314 & 180 & $\mathrm{~s} / \mathrm{i}$ & 11 \\
\hline 1914 & 306 & 160 & s/i & 13 \\
\hline 1915 & 348 & $\mathrm{~s} / \mathrm{i}$ & $\mathrm{s} / \mathrm{i}$ & 2 \\
\hline Total & ---- & ---- & 389 & 106 \\
\hline
\end{tabular}

FUENTE: elaboración propia a partir de los cuadros 5, 6, 7 y 8 de SÁnchez, "Escuela Nacional”, pp. 65-67, y López, “Aprendiendo a trabajar”, p. 131, tabla 2. 
Aun cuando no se dispone de información para todos los años, de acuerdo con los números reportados en la tabla, ${ }^{65} \mathrm{sa}-$ bemos que entre 1878 y 1915 sólo egresaron de la Escuela Nacional de Artes y Oficios para Hombres un total de 106 jóvenes, número extremadamente bajo que en promedio corresponde a 3.8 egresados al año en todo ese periodo. Por su parte, en los 43 años que reporta la tabla (de 1872 a 1915) y en los que el establecimiento registró la inscripción de alumnos, vemos que se otorgaron un total de 389 becas ( 16.9 becas por año en promedio), pero el número de egresados indica que ni con el otorgamiento de las becas se logró retener a los alumnos como para que concluyeran su formación. ${ }^{66}$ De hecho, si nos detenemos a evaluar año con año las cifras de inscripción respecto de la asistencia media se aprecia claramente la deserción e inasistencia como uno de los dos grandes problemas del establecimiento. En suma, que la contribución de la escuela, como la de otros establecimientos de su tipo, en la habilitación de mano de obra artesanal estuvo

${ }^{65}$ La información de la tabla 2 incorpora el total de becarios, información que no reportó Miguel López e incluye datos para un periodo mayor al estudiado en esta tesis doctoral. Por otra parte, a diferencia de Sánchez y López, no he sumado los totales de las columnas de número de inscripciones y asistencia media porque hacerlo es incorrecto, ya que la inscripción de un año incluye alumnos de nuevo ingreso lo mismo que alumnos que ya venían cursando y que se deben considerar como reinscripciones. Totalizar esta columna arroja datos incorrectos que sobreestiman el número de alumnos. Por otra parte, conviene aclarar que los totales que los autores reportan varían en relación con el periodo de estudio comprendido por cada uno, así como como por algunas diferencias que resultan de la consulta de los informes o de las actas de la Escuela de Artes y Oficios. SÁnchez, "Escuela”, pp. 65-67; y López, “Aprendiendo", p. 131.

${ }^{66}$ El promedio anual de egresados se obtiene al eliminar los años de los que no se dispone de información (14 años) y dividir los 106 egresados entre el número de años de los que se cuenta con información. Por su parte, para obtener el promedio de becas se procedió de la misma manera pues no se cuenta con la información para un total de 20 años. En este último caso convine tener en cuenta que se trata de becas y no de becarios. 
lejos de cubrir las aspiraciones del estado liberal de asumir la educación y la formación para el trabajo de la mano de obra.

Así lo reconocieron los ministros y más tarde secretarios de Instrucción y por ello se procedió a reformar el plan de estudios de la Escuela de Artes y Oficios para Hombres en dos momentos, pues se insistía en la necesidad de apoyar una mayor formación práctica y de establecer los talleres necesarios para poder conjugar la teoría con la práctica y con ello contribuir a formar mejores trabajadores. Sin duda que la principal atención de los responsables de la educación del país, Joaquín Baranda, Justino Fernández y Justo Sierra, se puso por una parte en la instrucción elemental y, por la otra, en la formación profesional, pero no en la formación de la mano de obra (artesanos, obreros o técnicos), pues las leyes del periodo relativas a la educación, tanto como los congresos higiénico-pedagógicos de 1889 y 1890, no se ocuparon detenidamente de la formación en las artes y los oficios, con todo y que en discurso se reconocía su importancia. ${ }^{67} \mathrm{De}$

${ }^{67}$ Véase Ley Orgánica de Instrucción Pública. Al iniciarse el porfiriato el ejecutivo intervino en educación. De hecho, desde 1876 se observa una progresiva estabilidad en la política educativa, sobre todo durante la administración de Joaquín Baranda. Antes de que éste ocupara el cargo en el ministerio, de 1876 a 1882 cinco personas se encargaron de llevar las riendas del Ministerio de Justicia e Instrucción Pública, a saber: Ignacio Ramírez (de noviembre de 1876 a mayo de 1877), Protacio P. Tagle (de mayo de 1877 a noviembre de 1879), Juan N. García (de noviembre a diciembre de 1879), Ignacio Mariscal (de diciembre de 1879 a diciembre de 1880) y Ezequiel Montes (de diciembre de 1880 a abril de 1882). Durante estos años, los ministros permanecieron poco tiempo en su cargo, el cambio de los encargados del ramo de instrucción no permitió un avance realmente importante y, de acuerdo con Josefina Z. Vázquez, poco es lo que se pudo lograr en materia educativa en esos años. Vázquez, Nacionalismo y educación; Pérez Toledo, "La educación”. Véase "Informe de José Díaz Covarrubias sobre el estado que Guarda la Instrucción Pública" elaborado para el año de 1875 y "Cuadro Estadístico (1881)". Aunque la fuente indica que el cuadro se refiere al Distrito Federal, de acuerdo con el Informe o Memoria del Ayuntamiento de 1885, todas las escuelas primarias y las de adultos se encontraban en la ciudad de México. Véase Memoria del Ayuntamiento, 1885, p. 65. 
hecho, Justo Sierra reconoció en 1902, y más tarde en 1907, el gran fracaso de la Escuela de Artes y Oficios para Hombres y la explicó precisamente por el hecho de que los programas de estudios eran fundamentalmente teóricos.

Durante la inauguración del Consejo Superior de Educación Pública, en septiembre de 1902, Justo Sierra afirmó que la "Escuela de Artes y Oficios para varones produce insignificantes resultados" y agregó que era necesaria "la restauración práctica de ese plantel que debía ser nuestro orgullo". ${ }^{68}$ Esa crítica está relacionada con el tipo de enseñanza, así como con el número de alumnos formados en la escuela, pero incluía también una crítica a la gestión como director de Manuel Álvarez, a quien se le había pedido su renuncia. Las diferencias entre ambos no constituyen un asunto central para este artículo, lo que sí importa es que en 1905 Justo Sierra asumió el control de las escuelas de artes y oficios de hombres y de mujeres, y con ello se emprendió la reforma al plan de estudios con la finalidad de dar mayor peso a la formación práctica, en consonancia con las reformas legales realizadas por el ejecutivo a toda la educación superior. En este contexto, en 1907 Sierra informó a la Cámara de Diputados en calidad de secretario del ramo sobre la organización de la Escuela de Artes y Oficios lo siguiente:

Por circunstancias que no es el caso referir [...] dichas escuelas no habían producido, según una serie de confesiones que es fácil recoger, los resultados apetecidos [...] aquí se trata de una obligación precisa, clara y terminantemente expresada en la Constitución: en uno de sus artículos se impone la obligación 'de crear escuelas prácticas de artes y oficios para la educación del pueblo'. [...] Quizá, señores, el mal de que estas instituciones han adolecido (al menos,

68 "Discurso pronunciado por el Subsecretario de Instrucción Pública, Justo Sierra, el día 13 de septiembre del año de 1902, con motivo de la inauguración del Consejo Superior de Educación Pública”, en Sierra, Obras, p. 317. 
después de estudios concienzudos sobre la materia, a esa conclusión hemos llegado) había consistido en que se exigían demasiados estudios teóricos a los alumnos, en que se les obliga a adquirir conocimientos simultáneos de oficios que estaban distribuidos en diversos talleres, por los cuales era forzoso que pasaran todos los alumnos de la Escuela de Artes y Oficios para varones. ${ }^{69}$

Según Justo Sierra este problema se eliminaría con la reforma, pues además de "perfeccionar sus conocimientos primarios" al llegar a la escuela aprenderían el dibujo, "este leguaje de la industria humana, sin el cual realmente el artesano no puede pretender salir de un estado inferior para pasar a otro superior". Podrían además concentrarse en el aprendizaje de un solo oficio con lo cual, indicaba Sierra, "Esperamos que el obrero mexicano formado en la Escuela de Artes y Oficios sea el principal elemento del progreso de los grupos industriales". ${ }^{70}$

Si observamos los datos de la tabla 2 relativos al número de egresado se puede ver que, a partir de 1902, año en que Álvarez dejó la dirección del establecimiento, se reporta un mayor número de egresados respecto de la década anterior. Sin embargo, en los años siguientes a la reforma al plan de estudios de 1907 apenas hay un modesto incremento anual de egresados, lo que sí parece indicar una mejora en la eficiencia de la Escuela de Artes y Oficios, pero tampoco es considerable comparado con el número de alumnos inscritos. Por otra parte, como se observa por el número de becas reportadas en estas dos décadas, el apoyo económico a los alumnos fue bastante reducido, lo que de manera indirecta podría indicar la poca importancia que en los

69 Justo Sierra, "Reformas legales a la educación superior. Discurso en la sesión en que se dio cuenta del informe rendido por el Ejecutivo de la Unión en cuanto al uso que ha hecho, hasta el 30 de marzo de 1907, de la autorización que le fue concedida para legislar en materia de enseñanza”, en SIERRA, Obras, pp. 382383.

70 Sierra, Obras, p. 383. 
hechos se concedía a la formación de los jóvenes de la Escuela más allá del discurso.

Para estos años, como sabemos, la crisis económica, así como las diferencias políticas entre los grupos de poder del régimen porfirista, las profundas contradicciones y los conflictos estructurales emergieron en la arena apenas tres años después de la reforma al plan de estudios de 1907 con el estallido de la revolución mexicana. A pesar de esas circunstancias, la Escuela siguió funcionando seguramente en condiciones de incertidumbre provocadas por la guerra. Finalmente, justo para el momento más crítico de la revolución en la ciudad de México entre 1912 y 1915, primero por la Decena Trágica, así como por el sitio de la ciudad, las enfermedades y la hambruna que vivieron los habitantes durante estos años aciagos, ${ }^{71}$ en los primeros días de 1915 cerró la Escuela y sus pocos estudiantes y maestros salieron hacia Veracruz.

\section{REFLEXIONES FINALES}

Sería una insensatez pensar que a lo largo de los más de cien años que transcurrieron entre las reformas a los gremios del último cuarto del siglo xviII, el decreto de libertad de oficio de 1813, los últimos años del siglo xIx, así como el inicio del siglo Xx no hubiera cambiado nada respecto de la enseñanza de las artes u oficios mecánicos. Oficios emergentes requerían de un nuevo tipo de mano de obra; la mecanización, la electricidad y los ferrocarriles, el desarrollo de centros fabriles de mayor tamaño en el Valle de México fueron sin duda cambios significativos, como lo fueron también los cambios en las formas de organización y lucha de los artesanos y obreros a partir de la década de 1860. Pero asumir sin matices, por un lado, "la transferencia de los oficios del gremio a la escuela pública”, incluso al finalizar

$\overline{71} \mathrm{Al}$ respecto véase KNIGHT, La Revolución; RodRíGUEz, Historia. 
la década de 1880 y, por el otro, afirmar que "El artesano virtuoso y honrado, orgulloso de su oficio e hijo del gremio, cedió su asiento al producto acabado de la escuela: el obrero calificado", ${ }^{72}$ son ideas que hay que revisar a la luz de un análisis que considere por una parte un periodo histórico más amplio como el abordado en este artículo, que permita tomar distancia de las interpretaciones excesivamente triunfalistas del estado liberal y de la modernidad porfiriana, así como de los discursos de la época que resultan de la revisión de las leyes y reglamentos propios del estado liberal, o bien de los que se pueden obtener al estudiar los informes y la prensa de la segunda mitad del siglo XIX con la finalidad de contrastarlos con la evidencia empírica que nos permite conocer y justipreciar los alcances y límites de este tipo de escuelas públicas, así como la capacidad del estado en la formación y reproducción de la mano de obra.

Como se planteó en las páginas anteriores, la formación de artesanos, la reproducción de los oficios en la ciudad de México (la mayoría de ellos de larga data, como el de los carpinteros, zapateros, tejedores y sastres, o bien los relacionados con el trabajo de los metales, entre otros) se mantuvo a cargo de los maestros de los pequeños talleres, cuyo número no se redujo a pesar de los innumerables problemas económicos, políticos y militares que fueron parte de la formación del nuevo estado durante prácticamente todo el siglo XIx y que contribuyeron al deterioro económico del artesanado. Sin embargo, las formas de sociabilidad artesana y la costumbre de entregar a niños y adolescentes a un maestro para que aprendiera un oficio, como se hacía desde el periodo colonial de acuerdo con las ordenanzas por medio de escritura o acuerdo de palabra, permitió que se mantuviera (seguramente no intacta) la estructura jerárquica de los oficios.

72 Illades, Hacia, pp. 141. Véase la nota 53. 
La prevalencia del pequeño taller como el espacio de enseñanza de los oficios o artes mecánicas en la capital no podía ser de otra manera si consideramos que las escuelas públicas de artes y oficios no pudieron desplazar al maestro de oficio en esta tarea, como se mostró no sólo al evaluar el conjunto de esfuerzos poco exitosos para establecer este tipo de escuelas debido a los serios problemas y dificultades que impuso la complicada realidad decimonónica a los distintos proyectos e iniciativas formuladas antes de 1867, sino también por los escasos resultados de la Escuela de Artes y Oficio para Hombres desde ese año y hasta 1915, fecha en la que se cerró el establecimiento con apenas 106 egresados a lo largo de más de cuatro décadas. Esto no puede ser evaluado sino como un gran fracaso en términos de su objetivo: contribuir a la formación del pueblo.

Sin duda, los discursos, ideas, leyes e instituciones del periodo tienen una importancia particular y peso específico, por lo que es importante estudiarlas, pero para comprender la reproducción de los oficios artesanales y la formación de la mano de obra en la ciudad de México durante todo este periodo estudiado aquí se requiere, propongo, una perspectiva más amplia (social y temporal). Es indispensable, además de confrontar los discursos con las prácticas, reflexionar acerca de los límites impuestos (con frecuencia autoimpuestos) por la historiografía que centra su atención por una parte en el estudio de la emergencia de la modernidad y del estado liberal del siglo xix, y por la otra, la que se ocupa del estudio del desarrollo de los centros fabriles y la industrialización mexicana, así como de las formas modernas de organización y lucha de los trabajadores. Perspectivas y enfoques que han contribuido al conocimiento de la historia sobre el periodo al igual que sobre temas y aspectos diversos relacionados con el problema estudiado en este ensayo, pero que, de forma indirecta y quizá sin proponérselo, han conducido a invisibilizar al pequeño taller y al artesanado urbano como sujeto histórico y como problema de estudio. 
En este sentido importa reconocer la enorme heterogeneidad social del mundo del trabajo de la ciudad de México, un espacio que creció considerablemente en territorio y población, una ciudad a la que llegaron el alumbrado eléctrico, los tranvías y la modernidad porfiriana con grandes fábricas de textiles, papel, cigarros, así como los grandes establecimientos comerciales, ${ }^{73}$ pero en la que no desaparecieron los pequeños talleres de los oficios más tradicionales de costumbres ancestrales que eran espacios de trabajo y de reproducción del artesanado que no se formó en la escuela pública de artes y oficios. ${ }^{74}$

\section{SIGLAS Y REFERENCIAS}

$\begin{aligned} \text { AHCM } & \text { Archivo Histórico de la Ciudad de México, México. } \\ \text { AGN } & \text { Archivo General de la Nación, Ciudad de México, México. }\end{aligned}$

Agulhon, Maurice, “Clase obrera y sociabilidad antes de 1848”, en Historia Social, 12 (invierno 1992), pp. 144-166.

Amaro Peñaflores, René, La educación popular en Zacatecas. De las primeras letras a las escuelas de artes y oficios: trabajadores, pobreza y laicización (1767-1897), México, Universidad Autónoma de Zacatecas, 2017.

Arrom, Silvia Marina, Containing the Poor. The Mexico City Poor Hose, 17741871, Durham, Duke University Press, 2000.

73 En la que los obreros constituyeron la fuerza “estratégica” de la que se ocupa Womack, o como se muestran en el conjunto de ensayos que integran el caleidoscopio de las instantáneas de la ciudad de México o la ciudad de la que se ocupa Mauricio Tenorio. Womack, Fuerza y El trabajo; SAlmerón y Aguayo, Instantáneas; Tenorio, Hablo. Véanse las notas 40 y 56.

74 No sólo porque egresaron muy pocos alumnos sino porque para ingresar a la Escuela de Artes y Oficios se debía contar con la escuela primaria elemental, pues había que saber leer y escribir. Al respecto hay que considerar que para 1895 sólo $37.73 \%$ de hombres y mujeres leían y escribían, en tanto que, para 1910, 50.21\% de la población del Distrito Federal podía leer y escribir. En cuanto a la población que no sabía leer y escribir, se pasó de $41.69 \%$ en el primer año a $25.79 \%$ en 1910. GonZÁLEZ, Estadísticas, pp. 123-125. 
Aquino Hernández, María del Carmen, "Cultivando al 'bello sexo'. La Escuela de Artes y Oficios para Mujeres, 1871-1876", tesis de licenciatura en historia, México, Universidad Nacional Autónoma de México, 2018.

Barbosa Cruz, Mario, El trabajo en las calles. Subsistencia y negociación política en la ciudad de México a comienzos del siglo XX, México, El Colegio de México, Universidad Autónoma Metropolitana-Cuajimalpa, 2008.

Barrio Lorenzot, Francisco del, Ordenanzas de gremios de la Nueva España, México, Secretaría de Gobernación, 1920.

Bazant, Mílada, "La capacitación del adulto al servicio de la Paz y del Progreso, 1876-1910”, en Historia de la alfabetización, 1994, t. 1, pp. 240-287.

Bazant, Mílada, Historia de la educación durante el porfiriato, México, El Colegio de México, 2006.

Beretta Curi, Alcides, Inmigración europea e industria. Uruguay en la región (1870-1915), Montevideo, Universidad de la República del Uruguay, 2015.

BERG, Maxine, La era de las manufacturas 1700-1820. Una nueva historia de la Revolución industrial británica, Barcelona, Crítica, 1987.

Bermúdez de Brauns, María Teresa, "Una población instruida, base de la sobrevivencia nacional”, en Historia de la alfabetización, 1994, t. 1, pp. 184-239.

Bracho, Julio, De los gremios al sindicalismo. Genealogía corporativa, México, Universidad Nacional Autónoma de México, 1990.

Burke, Peter, Cultura popular en la Europa moderna, Madrid, Alianza Editorial, 2014.

CARRera StAmpa, Manuel, Los gremios mexicanos. La organización gremial en Nueva España 1521-1861, México, Universidad Nacional Autónoma de México, 1954.

Castro Gutiérrez, Felipe, La extinción de la artesanía gremial, México, Universidad Nacional Autónoma de México, 1986.

Chaoul Pereyra, María Eugenia, Entre la esperanza del cambio y la continuidad de la vida. El espacio de las escuelas primarias nacionales en la ciudad 
de México, 1891-1919, México, Instituto de Investigaciones Dr. José María Luis Mora, 2014.

Chávez Orozco, Luis, La agonía del artesanado, México, Centro de Estudios Históricos sobre el Movimiento Obrero, 1977.

Costeloe, Michael P., La primera república federal de México (1824-1835). Un estudio de los partidos políticos en el México independiente, México, Fondo de Cultura Económica, 1975.

Costeloe, Michael P., La república central en México, 1835-1846. "Hombres de bien" en la época de Santa Anna, México, Fondo de Cultura Económica, 2000.

Dublán, Manuel y José María Lozano, Legislación mexicana o Colección completa de las disposiciones legislativas expedidas desde la Independencia de la República, México, Imprenta de Comercio, 1876, 34 vols.

Eguiarte SaKar, María Estela, Hacer ciudadanos. Educación para el trabajo manufacturero en el siglo XIX, México, Universidad Iberoamericana, 1989.

FARGE, Arlette, La vida frágil. Violencia, poderes y solidaridad en el París del siglo XVIII, México, Instituto de Investigaciones Dr. José María Luis Mora, 1994.

Frost, Elsa y Josefina Z. VÁzQuez (comps.), El trabajo y los trabajadores en la historia de México, México, Tucson, El Colegio de México, University of Arizona Press, 1979.

GanTús, Fausta (coord.), Elecciones en el México del siglo XIX. Las prácticas, México, Instituto de Investigaciones Dr. José María Luis Mora, 2016, t. I.

Gómez-Galvarriato, Aurora, "Fragilidad institucional y subdesarrollo: la industria textil mexicana en el siglo xIx", en Gómez-GalvarRiato (coord.), 1999, pp. 142-182.

Gómez-Galvarriato, Aurora, Industria y revolución. Cambio económico y social en el valle de Orizaba, México, Fondo de Cultura Económica, El Colegio de México, Universidad Veracruzana, 2016.

Gómez-Galvarriato, Aurora (coord.), La industria textil en México, México, Instituto de Investigaciones Dr. José María Luis Mora, El Colegio de 
Michoacán, El Colegio de México, Universidad Nacional Autónoma de México, 1999.

Gonzalbo Aizpuru, Pilar, Vivir en la Nueva España. Orden y desorden en la vida cotidiana, México, El Colegio de México, 2009.

Gonzalbo Aispuru, Pilar y Anne Staples, Historia de la educación en la cindad de México, México, El Colegio de México, Secretaría de Educación Pública, 2012.

González Angulo, Jorge, Artesanado y cindad a finales del siglo XVIII, México, Secretaría de Educación Pública, Fondo de Cultura Económica, 1983.

González Navarro, Moisés, Estadísticas sociales del Porfiriato, México, Secretaría de Economía, 1956.

González Navarro, Moisés, Historia moderna de México. El Porfiriato. La vida social, México, Hermes, 1957.

Guerra, François-Xavier, México: del Antiguo Régimen a la Revolución, México, Fondo de Cultura Económica, 1988.

GutiérRez, Florencia, El mundo del trabajo y el poder político. Integración, consenso y resistencia de la ciudad de México a fines del siglo XIX, México, El Colegio de México, 2011.

Haber, Stephen, "Mercados financieros y desarrollo industrial en Brasil y México, 1840-1930”, en Gómez-Galvarriato (coord.), 1999, pp. 183-223.

Historia de la alfabetización y de la educación de adultos en México, t. 1, México, Secretaría de Educación Pública, Seminario de Historia de la Educación de El Colegio de México, 1994.

Hoвsвашм, Eric, El mundo del trabajo. Estudios históricos sobre la formación y evolución de la clase obrera, Barcelona, Crítica, Grijalbo, 1987.

Illades, Carlos, Hacia la república del trabajo. La organización artesanal en la cindad de México, 1853-1876, México, Universidad Autónoma Metropolitana, El Colegio de México, 1996.

Illades, Carlos y Ariel Rodríguez (comps.), Ciudad de México. Instituciones, actores sociales y conflicto político, 1774-1931, México, El Colegio de Michoacán, Universidad Autónoma Metropolitana, 1996. 
Illades Carlos y Mario BARbosa (coords.), Los trabajadores de la cindad de México 1860-1950. Textos en homenaje a Clara E. Lida, México, El Colegio de México, Universidad Autónoma Metropolitana, 2013.

"Impreso. Recopilación de noticias sobre el Comercio de contrabando con las posesiones de España en América", en Boletín del Archivo General de la Nación, xxix: 4 (oct., nov., dic. 1958), pp. 611-704.

Johnson, Lyman L., Los talleres de la revolución. La Buenos Aires plebeya y el mundo del Atlántico, 1776-1810, Buenos Aires, Prometeo Libros, 2013.

Knight, Alan, La Revolución mexicana, México, Fondo de Cultura Económica, 2010.

KocKA, Jürgen, "Los artesanos, los trabajadores y el Estado: hacia una historia social de los comienzos del movimiento obrero alemán”, en Historia Social, 12 (invierno 1992), pp. 101-118.

LEAR, John, "Del mutualismo a la resistencia: las organizaciones laborales en la ciudad de México de fines del porfiriato a la revolución", en Illades y RODRÍGUEZ (comps.), 1996, pp. 275-309.

Lear, John, Workers, Neighbors, and Citizens. The Revolution in Mexico City, Lincoln, University of Nebraska Press, 2001.

Ley Orgánica de Instrucción Pública en el Distrito Federal. 1867-1967. Reglamento/Oración Cívica, México, Universidad Nacional Autónoma de México, 1967.

Ley Reglamentaria de la Instrucción Obligatoria en el Distrito Federal y Territorios, México, Imprenta del Gobierno en el Ex-Arzobispado, 1900.

Libro de Autos, cabildos y elecciones del gremio de Plateros, Tiradores y Vatiogas [Batihojas] de oro, dos vols., 1689-1848.

Lida, Clara E. y Sonia Pérez Toledo (coords.), Trabajo, ocio y coacción. Trabajadores urbanos en México y Guatemala en el siglo XIX, México, Universidad Autónoma Metropolitana-Iztapalapa, Miguel Ángel Porrúa, 2001.

Loaiza Cano, Gilberto, Sociabilidad, religión y politica en la definición de la nación, Bogotá, Universidad Externado de Colombia, 2011. 
Lombardo de Ruiz, Sonia (coord.), El quehacer de censar. Cuatro historias, México, Instituto Nacional de Antropología e Historia, 2006.

López Domínguez, Miguel, “Aprendiendo a trabajar en la ciudad de México. La formación laboral en las Escuelas Nacionales de Artes y Oficios para Hombres y Mujeres, 1880-1911", tesis de doctorado en historia, México, El Colegio de México, 2019.

Lorenzo Río, María Dolores, El Estado como benefactor. Los pobres y la asistencia pública en la ciudad de México, 1877-1905, México, El Colegio de México, El Colegio Mexiquense, 2011.

Lorenzo, María Dolores, "Los contratos de concesión de la Beneficencia Pública 'Ingeniosas prácticas' para la formación de indigentes durante el porfiriato”, en Pérez Toledo (coord.), 2012, pp. 145-158.

Márquez Martínez, Aída Enriqueta, "La Escuela Nacional de Artes y Oficios de Hombres”, tesis de licenciatura en historia, México, ENEP Acatlán, Universidad Nacional Autónoma de México, 1992.

Memoria Económica de la Municipalidad de México formada por orden del Excmo. Ayuntamiento en 1830, México, Imprenta de Martín Rivera a cargo de Tomás Uribe, 1830.

Memoria del Ayuntamiento, México, Tipografía de Gonzalo A. Esteva, 1885.

Memoria del Secretario de Estado y del despacho de Relaciones Exteriores e Interiores, México, 1831.

Memoria o Manifiesto al Público que hace el Ayuntamiento de 1840, México, Impresión de Ignacio Cumplido, 1840.

Meneses Morales, Ernesto, Tendencias educativas oficiales de México, 18211911, México, Porrúa, 1983.

Mentz, Brígida von, Trabajo, sujeción y libertad en el centro de la Nueva España. Esclavos, aprendices, campesinos y operarios manufactureros, siglos XVI a XVIII, México, Centro de Investigaciones y Estudios Superiores en Antropología Social, Miguel Ángel Porrúa, 1999.

Miño Grijalva, Manuel, "Espacio económico e industria textil: los trabajadores de la Nueva España 1780-1810”, en Historia Mexicana, xxxir: 4 (128) (abr.-jun., 1983), pp. 524-553. 
Miño Grijalva, Manuel, Obrajes y tejedores de Nueva España (1700-1810), Madrid, Instituto de Cooperación Iberoamericana, Instituto de Estudios Fiscales, 1990.

Miño Grijalva, Manuel, La protoindustria colonial hispanoamericana, México, Fondo de Cultura Económica, El Colegio de México, 1993.

Miño Grijalva, Manuel, El obraje. Fábricas primitivas en el mundo hispanoamericano en los albores del capitalismo (1530-1850), México, El Colegio de México, 2016.

Mora, José María Luis, Obras completas, México, Instituto de Investigaciones Dr. José María Luis Mora, Secretaría de Educación Pública, 1986.

Montes, Ezequiel, Memoria de Justicia e Instrucción Pública, 1878-1881, México, Tipografía Literaria de F. Montes, 1881.

Morales Martínez, María Dolores, "El Padrón de la Municipalidad de México en 1882”, en Lombardo (coord.), pp. 101-139.

Olmedo González, José de Jesús, “Ambrosio de Sagarzurieta. Un personaje ilustrado", en Caravelle, Cahiers du monde hispanique et luso-brésilien, 81 (2003), pp. 49-59.

Orduña Carson, Miguel, “Ensayo sobre el modelo liberal de organización social. Artesanos mexicanos y sus mutualidades en la segunda mitad del siglo XIX”, en BeretTA Curi (coord.), 2015, pp. 87-112.

Pérez Toledo, Sonia, Los hijos del trabajo. Los artesanos de la ciudad de México 1780-1853, México, Universidad Autónoma Metropolitana-Iztapalapa, El Colegio de México, 1996.

Pérez Toledo, Sonia, Trabajadores, espacio urbano y sociabilidad en la ciudad de México, 1790-1867, México, Universidad Autónoma MetropolitanaIztapalapa, Miguel Ángel Porrúa, 2011.

Pérez Toledo, Sonia, “¿La autogestión educativa en los grupos laborales? Del gremio a las organizaciones obreras del siglo XIX”, en Ríos y LeYva, (coords.), 2015, pp. 149-180.

Pérez Toledo, Sonia, "Elecciones en la ciudad de México en las décadas de 1830-1840: los actores”, en GaNTús (coord.), 2016, pp. 317-342. 
Pérez Toledo, Sonia, "La trama de la costumbre frente a los cambios. Los gremios de oficios y el Ayuntamiento de la ciudad de México", en Rojas, (coord.), 2017, pp. 321-350.

Pérez Toledo, Sonia, "La educación elemental de la ciudad de México y la formación de la conciencia nacional durante el porfiriato 1876-1910", México, tesis de maestría en historia, Universidad Autónoma MetropolitanaIztapalapa, 1987.

Pérez Toledo, Sonia (coord.), Trabajo, trabajadores y participación popular. Estudios sobre México, Guatemala, Colombia, Perú y Chile, siglos XVIII y XIX, México, Ánthropos, Universidad Autónoma Metropolitana, 2012.

Porter, Susie S., Mujeres y trabajo en la ciudad de México. Condiciones materiales y discursos públicos (1879-1931), México, El Colegio de Michoacán, 2008.

Potash, Robert A., El Banco de Avío de México. El fomento de la industria, 1821-1846, México, Fondo de Cultura Económica, 1986.

Ramos Escandón, Carmen, Industrialización, género y trabajo femenino en el sector textil mexicano: el obraje, la fábrica y la compañia industrial, México, Centro de Investigaciones y Estudios Superiores en Antropología Social, 2005.

Ríos, Rosalina y Juan Leyva (coords.), Voz popular, saberes no oficiales: bumor, protesta, disidencia y organización desde la escuela, la calle y los márgenes (México, siglo XIX), México, Universidad Nacional Autónoma de México, Instituto de Investigaciones sobre la Universidad y la Educación, 2015.

Rivera Cambas, Manuel, México pintoresco, artístico y monumental, México, Editorial del Valle de México, 1882, t. 2.

Rodríguez de Campomanes, Pedro, Discurso sobre la educación popular de los artesanos y su fomento, Madrid, Imprenta de Antonio de Sánchez, 1775.

Rodríguez Kuri, Ariel, Historia del desasosiego. La revolución en la ciudad de México, 1911-1922, México, El Colegio de México, 2010.

Rojas, Beatriz (coord.), Procesos constitucionales mexicanos: la Constitución de 1824 y la antigua constitución, México, Instituto de Investigaciones Dr. José María Luis Mora, 2017.

Salmerón, Alicia y Fernando Aguayo (coords.), “Instantáneas" de la Ciudad de México. Un álbum de 1883-1884, México, Instituto de Investigaciones Dr. 
José María Luis Mora, Fondo Cultural Banamex, Comité Mexicano de Ciencias Históricas, Universidad Autónoma Metropolitana-Cuajimalpa, 2013, ts. I y II.

Salvucci, Richard J., Textiles y capitalismo en México. Una historia económica de los obrajes, 1539-1840, México, Alianza Editorial, 1992.

Sánchez Meneses, María de Jesús, "Escuela Nacional de Artes y Oficios para Hombres. Discurso y vida cotidiana (1867-1915)", tesis de maestría en historia, México, Instituto Politécnico Nacional, 2003.

Sewell, William Jr., "Social Change and the Rise of Working-class Politics in Nineteenth Century Marseille”, en Past and Present, 65 (feb. 1974), pp. 75-109.

SEwELL, William Jr., Work and Revolution in France. The Language of Labor from the Old Regime to 1848, Nueva York, Cambridge University Press, 1987.

SEWELL, William Jr., "Los artesanos, los obreros de las fábricas y la formación de la clase obrera francesa”, en Historia Social, 12 (invierno 1992), pp. 119-140.

Sierra, Justo, Obras completas del maestro Justo Sierra, México, Universidad Nacional Autónoma de México, 1994, t. 5.

Sordo Cedeña, Reynaldo, El Congreso en la primera república centralista, México, El Colegio de México, Instituto Tecnológico Autónomo de México, 1993.

Sowell, David, Artesanos y política en Bogotá, Bogotá, Ediciones Plural, 2017.

Staples, Anne, Educar:panacea del México independiente, México, Secretaría de Educación Pública, El Caballito, 1985.

STAPles, Anne, "La lectura y los lectores en los primeros años del siglo XIX", en Historia de la lectura en México, México, El Colegio de México, 1988, pp. 94-126.

Staples, Anne, "Leer y escribir en los estados del México independiente", en Historia de la alfabetización, 1994, t. 1, pp. 133-183.

TAnck de Estrada, Dorothy, La educación ilustrada, 1786-1836, México, El Colegio de México, 1984.

Tanck de Estrada, Dorothy, "La abolición de los gremios", en Frost y VÁzQueZ (comps.), 1979, pp. 311-331. 
TANCK De Estrada, Dorothy, "Reformas borbónicas y educación utilitaria, 1700-1821”, en Historia de la alfabetización, 1994, t. 1, pp. 67-104.

TAnck de Estrada, Dorothy, "La alfabetización: medio para formar ciudadanos de una democracia, 1821-1840", en Historia de la alfabetización, 1994, t. 1, pp. 107-132.

Teitelbaum, Vanesa E., “Asociación y protesta de los artesanos al despuntar la década de 1860”, en Illades y Barbosa (coords.), 2013, pp. 51-80.

Tenorio TriLlo, Mauricio, "Hablo de la ciudad". Los principios del siglo XX desde la Ciudad de México, México, Fondo de Cultura Económica, 2017.

Thompson, E. P., Costumbres en común, Barcelona, Crítica, 1993.

Thompson, E. P., Tradición, revuelta y conciencia de clase, Barcelona, Crítica, Grijalbo, 1979.

Thomson, Guy, "Continuidad y cambio en la industria manufacturera mexicana, 1800-1870”, en GómEZ-GalvarRiato (coord.), 1999, pp. 53-113.

Trujillo Bolio, Mario, Operarios fabriles en el Valle de México, 1864-1884, México, Centro de Investigaciones y Estudios Superiores en Antropología Social, El Colegio de México, 1997.

VÁzquez, Josefina Z., "Iglesia, ejército y centralismo”, en Historia Mexicana, xxxix: 1 (153) (jul.-sep. 1989), pp. 205-235.

VÁzquez, Josefina Z., Nacionalismo y educación en México, México, El Colegio de México, 1979.

VÁzquez, Josefina Z., Dos décadas de desilusiones, en busca de una forma adecuada de gobierno (1832-1854), México, El Colegio de México, Instituto de Investigaciones Dr. José María Luis Mora, 2009.

Womack Jr., John, Posición estratégica y fuerza obrera. Hacia una nueva historia de los movimientos obreros, México, El Colegio de México, Fondo de Cultura Económica, 2007.

Womack Jr., John, El trabajo en la Cervecería Moctezuma 1908, México, El Colegio de México, Fideicomiso Historia de las Américas, H. Congreso del Estado de Veracruz LXII Legislatura, 2012. 